\title{
Type B and Type A influenza polymerases have evolved distinct binding interfaces to recruit the RNA polymerase II CTD
}

${ }^{1}$ RNA Biology and Influenza Virus Unit, Institut Pasteur, CNRS UMR3569, Université de

11 Paris, Paris, France

$12{ }^{2}$ European Molecular Biology Laboratory, 71 Avenue des Martyrs, CS 90181, 38042 Grenoble

13 Cedex 9, France

$14{ }^{3}$ PRABI, Rhône Alpes Bioinformatics Center, UCBL, Lyon1, Université de Lyon, Lyon, 15 France.

16

* Current address: Department of Molecular and Cell Biology, University of California, 18 Berkeley, Berkeley, CA 94720, USA

19

20 \# co-corresponding authors:

21 Nadia Naffakh E-mail: nadia.naffakh@pasteur.fr

22 Stephen Cusack E-mail : cusack@embl.fr

25 Short title: Evolutionary divergence of influenza polymerase/host RNAPII interface 


\section{Abstract}

During annual influenza epidemics, influenza B viruses (IBVs) co-circulate with influenza A viruses (IAVs), can become predominant and cause severe morbidity and mortality. Phylogenetic analyses suggest that IAVs (primarily avian viruses) and IBVs (primarily human viruses) have diverged over long time scales. Identifying their common and distinctive features is an effective approach to increase knowledge about the molecular details of influenza infection. The virus-encoded RNA-dependent RNA polymerases $\left(\right.$ FluPol $_{\mathrm{B}}$ and $\left.\mathrm{FluPol}_{\mathrm{A}}\right)$ are PB1-PB2-PA heterotrimers that perform transcription and replication of the viral genome in the nucleus of infected cells. Initiation of viral mRNA synthesis requires a direct association of FluPol with the host RNA polymerase II (RNAP II), in particular the repetitive C-terminal domain (CTD) of the major RNAP II subunit, to enable "cap-snatching” whereby 5'-capped oligomers derived from nascent RNAP II transcripts are pirated to prime viral transcription. Here, we present the first high-resolution co-crystal structure of FluPol${ }_{\mathrm{B}}$ bound to a CTD mimicking peptide at a binding site crossing from PA to PB2. By performing structure-based mutagenesis of FluPol${ }_{\mathrm{B}}$ and $\mathrm{FluPol}_{\mathrm{A}}$ followed by a systematic investigation of FluPol-CTD binding, FluPol activity and viral phenotype, we demonstrate that IBVs and IAVs have evolved distinct binding interfaces to recruit the RNAP II CTD, despite the CTD sequence being highly conserved across host species. We find that the PB2 627 subdomain, a major determinant of FluPol-host cell interactions and IAV host-range, is involved in CTD-binding for IBVs but not for IAVs, and we show that FluPol${ }_{B}$ and FluPol$A$ bind to the host RNAP II independently of the CTD. Altogether, our results strongly suggest that the CTD-binding modes of IAV and IBV represent avian- and human-optimized binding modes, respectively, and that their divergent evolution was shaped by the broader interaction network between the FluPol and the host transcriptional machinery. 


\section{Authors summary}

During seasonal influenza epidemics, influenza B viruses (IBVs) co-circulate with influenza A viruses (IAVs) and can cause severe outcomes. The influenza polymerase is a key drug target and it is therefore important to understand the common and distinctive molecular features of IBV and IAV polymerases. To achieve efficient transcription and replication in the nucleus of infected cells, influenza polymerases closely cooperate with the cellular RNA polymerase II (RNAP II) and interact with the repetitive C-terminal domain (CTD) of its major subunit. Here we gained new insights into the way IBV and IAV polymerases interact with the CTD of RNAP II. High-resolution structural data was used to perform structure-based mutagenesis of IBV and IAV polymerases followed by a systematic investigation of their interaction with RNAP II, transcription/replication activity and viral phenotype. Strikingly, we found that IBVs and IAVs have evolved distinct interfaces to interact with the host transcriptional machinery, in particular with the CTD of RNAP II. We provide evidence that these differences may have evolved as a consequence of the differences in IBV and IAV host range. Our findings are of significant importance with regard to the development of broad-spectrum antivirals that target the virushost interface. 


\section{Introduction}

Influenza viruses are members of the Orthomyxoviriridae family and are classified into four genera: influenza A, B, C and D viruses. Influenza A viruses (IAVs) and influenza B viruses (IBVs) are of public health importance, as they co-circulate in humans with a seasonal epidemic pattern and cause a significant morbidity and mortality, especially in the aged or immunocompromised population [1]. IBV infections account for an estimated $23 \%$ of all influenza cases [2], can become predominant during annual influenza epidemics, and can cause severe disease in children [3]. IBVs have received less attention because, unlike IAVs which continuously circulate in a wide range of birds and mammalian species [4], they have no known potential to cause pandemics. Based on sequence analysis of the viral hemagglutinin, the evolutionary divergence between IBVs and IAVs was estimated to have occurred about 4000 years ago [5]. The recent identification of IBV-like viruses in non-mammalian vertebrate species suggest that IBVs and IAVs have actually diverged over much longer time scales [6].

IBVs and IAVs share the same genome organization of eight single-stranded negative RNA segments, and major features of the viral replication cycle such as transcription and replication of the viral genome in the nucleus of infected cells. However their genes have undergone functional divergence, as reflected notably by the lack of intertypic genetic reassortment [7]. To identify common and distinctive features of IBVs and IAVs is an effective approach to improve our understanding of the molecular mechanisms of influenza infection and our ability to fight influenza disease.

The genomic RNA segments of IAVs and IBVs are organized into viral ribonucleoprotein complexes (vRNPs) [8]. In the vRNP, the $5^{\prime}$ and $3^{\prime}$ terminal viral RNA sequences are associated with one copy of the RNA-dependent RNA polymerase complex (FluPol) while the RNA is covered by multiple copies of the viral nucleoprotein (NP) [9-11]. FluPol is a heterotrimer composed of PB1 (polymerase basic protein 1), PB2 (polymerase basic protein 2), and PA (polymerase acidic protein) [12], which replicates and transcribes the viral RNA in the nucleus 
of infected host cells. Replication is a primer-independent two-step process, which relies on de novo initiation by FluPol $[13,14]$. In contrast, viral transcription is primer-dependent and results in the synthesis of $5^{\prime}$ capped and $3^{\prime}$ polyadenylated mRNAs, which are translated by the host translation machinery $[15,16]$. Polyadenylation is achieved by stuttering of FluPol at a $5^{\prime}$ proximal oligo(U) stretch present on the genomic RNA $[17,18]$. In contrast to other RNA virus polymerases, FluPol cannot synthesize $5^{\prime}$ cap structures [19]. In a process referred to as capsnatching [20], FluPol binds the 5' cap of nascent host RNA polymerase II (RNAP II) transcripts by the PB2 cap-binding domain. Then, the PA endonuclease domain [21] cleaves 10-15 nts downstream of the 5' cap thereby generating primers that are used by FluPol to initiate transcription $[18,19,22]$.

To perform cap-snatching, FluPol needs access to nascent capped RNAP II-derived RNAs, which represents a challenge as host cap structures are rapidly sequestered co-transcriptionally by the cap-binding complex [23]. The cellular RNAP II consists of 12 subunits [24], and the largest subunit (RPB1) is characterised by a unique long unstructured C-terminal domain (CTD) which in mammals consists of 52 repeats of the consensus sequence Tyr-Ser-Pro-Thr-Ser-ProSer $\left(\mathrm{Y}_{1} \mathrm{~S}_{2} \mathrm{P}_{3} \mathrm{~T}_{4} \mathrm{~S}_{5} \mathrm{P}_{6} \mathrm{~S}_{7}\right)$. Post-translational modifications of the CTD during the transcription process are controlling the spatiotemporal regulation of RNAP II transcription $[25,26]$. FluPol binds specifically to S5 phosphorylated CTD (CTD pS5) [27,28] and it was proposed that it targets RNAP II for cap-snatching in the paused elongation state, of which CTD pS5 is the hallmark modification [29-31].

Structural studies revealed bipartite CTD binding sites on the FluPol of influenza A, B and C viruses $\left(\right.$ FluPol$_{\mathrm{A}}$, FluPol $_{\mathrm{B}}$ and FluPol $\left._{\mathrm{C}}\right)$ with notable differences from one type to another $[32,33]$. However, the original crystal structure data for FluPol ${ }_{\mathrm{B}}$ were of insufficient resolution and only one of the CTD binding sites could be modelled, therefore preventing functional studies. In this study, we report the first high-resolution co-crystal structure of FluPol ${ }_{\mathrm{B}}$ bound to a CTD pS5 mimicking peptide that allows the modelling of both CTD-binding sites, one exclusively on PA 
124 also observed on FluPol $_{\mathrm{A}}$, and another, crossing from PA to PB2, specific for FluPol $\mathrm{B}$. We used

125 these novel data to perform structure-guided mutagenesis of FluPol${ }_{\mathrm{B}}$ and $\mathrm{FluPol}_{\mathrm{A}}$, followed by

126 a systematic investigation of cell-based CTD-binding, cell-based polymerase activity and

127 plaque phenotype of recombinant viruses. Our findings demonstrate that type B and type A

128 influenza polymerases have evolved distinct binding interfaces to recruit the RNAP II CTD,

129 which is intriguing as the RNAPI II CTD is highly conserved across influenza host species. We

130 find that the PB2 627 subdomain, a major determinant of FluPol-host cell interactions and IAV

131 host-range, is involved in CTD-binding for IBVs but not for IAVs. Finally, we provide evidence

132 for additional FluPol-RNAP II interactions that do not involve the CTD.

133 


\section{Materials and Methods}

135 Purification, crystallisation, data collection and structure determination of FluPolB with

136 bound CTD peptide

137 Influenza B/Memphis/13/2003 polymerase, wild type or with the PA K135A mutation to

138 eliminate endonuclease activity, was expressed and purified as described previously [22].

139 For crystals enabling high resolution visualisation of CTD binding in site 2B, FluPol $\mathrm{B}$ PA

140 mutant $\mathrm{K} 135 \mathrm{~A}$ at $9 \mathrm{mg} \mathrm{ml}^{-1}(35 \mu \mathrm{M})$ was mixed with $40 \mu \mathrm{M}$ of nucleotides 1-13 vRNA 5 ' end

141 (5'-pAGUAGUAACAAGA-3') and $1.8 \mathrm{mM} \mathrm{28-mer} \mathrm{CTD} \mathrm{peptide} \mathrm{(YSPTpSPS})_{4}$ in a buffer 142 containing $50 \mathrm{mM}$ HEPES pH 7.5, $500 \mathrm{mM} \mathrm{NaCl}, 5 \%$ glycerol, $2 \mathrm{mM}$ TCEP. Hanging drops

143 for crystallisation were set up at $20^{\circ} \mathrm{C}$. Rod-shaped crystals growing up to $700 \mu \mathrm{m}$ in length 144 appeared one week after set-up in mother liquor containing $100 \mathrm{mM}$ tri-sodium citrate and $13 \%$

145 PEG 3350 with a drop ratio of $0.5 \mu 1+2 \mu 1$ protein to well solution. Crystals were cryo146 protected with additional $20 \%$ glycerol and $1.8 \mathrm{mM}$ CTD peptide in mother liquor and flash-

147 frozen in liquid nitrogen. Data were collected on ESRF beamline ID29 and integrated with an 148 ellipsoidal mask using AUTOPROC/STARANISO to an anisotropic resolution of 2.42-2.95 A.

149 The structure was solved using molecular replacement with PHASER [34] using PDB:5FMZ 150 as model [35]. The model was iteratively corrected and refined using COOT [36] and 151 REFMAC5 [37] and quality-controlled using MOLPROBITY [38]. See Table 1 for data 152 collection and refinement statistics.

153 For crystals enabling simultaneous visualisation of CTD binding in sites $2 \mathrm{~A}$ and $2 \mathrm{~B}$, wild type 154 FluPol $_{\mathrm{B}}$ at $11.7 \mathrm{mg} \mathrm{m} \mathrm{m}^{-1}(45 \mu \mathrm{M})$ was mixed with $52 \mu \mathrm{M}$ of nucleotides 1-14 (5'pAGUAGUAACAAGAG-3') and 1-18 (5'-UAUACCUCUGCUUCUGCU-3') of respectively the vRNA $5^{\prime}$ and $3^{\prime}$ ends, $104 \mu \mathrm{M}$ of capped $13-\operatorname{mer}\left(5^{\prime}-\mathrm{m}^{7} \mathrm{GpppAAUCUAUAAUAGC}-3^{\prime}\right)$, and $380 \mu \mathrm{M}$ CTD 28-mer Ser5P peptide, in buffer containing $50 \mathrm{mM}$ HEPES pH 7.5, $500 \mathrm{mM} \mathrm{NaCl}$,

$1585 \%$ glycerol, $2 \mathrm{mM}$ TCEP. Hanging drops for crystallisation were set up at $4^{\circ} \mathrm{C}$. Diamond- 
159 shaped crystals growing up to $200 \mu \mathrm{m}$ in size appeared in two to three weeks in mother liquor

160 containing $200 \mathrm{mM}$ di-ammonium phosphate, and $100 \mathrm{mM}$ sodium acetate at $\mathrm{pH} 4.4$, with a

161 drop ratio of $1 \mu \mathrm{l}+2 \mu \mathrm{l}$ protein to well solution. The drops were soaked with $840 \mu \mathrm{M}$ CTD

162 peptide for 17 days. Crystals were cryo-protected with an additional $30 \%$ glycerol and $885 \mu \mathrm{M}$

163 peptide in mother liquor and flash-frozen in liquid nitrogen. Data were collected on ESRF

164 beamline ID30A1 (MASSIF) and processed and refined as described above, using PDB:5MSG

165 as model for molecular replacement. See Table 1.

166

Structure determination of FluPol$(\mathbf{A}(\mathrm{H} 7 \mathrm{~N} 9)$ core with bound CTD peptide

The core of influenza A/Zhejiang/DTID-ZJU01/2013(H7N9) polymerase comprising PA 201previously [18]. A/H7N9 polymerase core at a concentration of $9 \mathrm{mg} / \mathrm{ml}$ was co-crystallised with $60 \mu \mathrm{m}$ of a 12-mer of the vRNA $5^{\prime}$ end (5'-pAGUAGUAACAAG) in sitting drops at $4^{\circ} \mathrm{C}$ in conditions of $0.1 \mathrm{M}$ Tris $\mathrm{pH} 7.0,13 \%$ PEG 8K, $0.2 \mathrm{M} \mathrm{MgCl}_{2}, 0.1 \mathrm{M}$ guanidine hydrochloride with drop mixing ratios of 1:2 (protein:well). Crystals grew typically within 4-5 days and

174 diffracted to around $3.5 \AA$ resolution. A four-repeat pS5 CTD mimicking peptide (Tyr-Ser-

175 Pro-Thr-pSer-Pro-Ser $)_{4}$ was soaked into existing crystals at a concentration of $\sim 2 \mathrm{mM}$ over a

176 period of $24 \mathrm{~h}$. Data were collected on ESRF beamline ID29 and processed and refined as

177 described above, using previously described apo-H7N9 core structure ([39], PDB:6TU5) as model for molecular replacement. See Table 1 for data collection and refinement statistics. 
bioRxiv preprint doi: https://doi.org/10.1101/2022.02.04.479088; this version posted February 4,2022 . The copyright holder for this preprint (which was not certified by peer review) is the author/funder, who has granted bioRxiv a license to display the preprint in perpetuity. It is made available under aCC-BY 4.0 International license.

Table 1. Crystallographic data collection and refinement statistics.

\begin{tabular}{|c|c|c|c|}
\hline Crystal & $\begin{array}{l}\text { B/Memphis polymerase } \\
(\mathrm{WT})+3^{\prime} \text { vRNA } 1-18 \\
+5^{\prime} \text { vRNA } 1-13 \\
+13 \text {-mer capped RNA } \\
\text { 28-mer CTD }\end{array}$ & $\begin{array}{l}\text { B/Memphis } \\
\text { polymerase (PA } \\
\text { K135A) } \\
+5 \text { ' vRNA 1-14 } \\
\text { 28-mer CTD }\end{array}$ & $\begin{array}{l}\text { A/H7N9 polymerase core } \\
\text { 201-PA_PB1_PB2-127 } \\
\text { 12-mer 5' vRNA } \\
\text { pSer5 28-mer CTD } \\
\text { peptide }\end{array}$ \\
\hline \multicolumn{4}{|l|}{ Diffraction Data } \\
\hline Space group & $P 3_{2} 21$ & $P 2_{1}$ & $P 2_{1} 2_{1} 2_{1}$ \\
\hline Cell dimensions $(\AA)$ & $\mathrm{a}=\mathrm{b}=200.82, \mathrm{c}=257.02$ & $\begin{array}{l}a=130.93, b=202.27, \\
c=135.73, \beta=110.54^{\circ}\end{array}$ & $\begin{array}{l}a=76.47, b=144.13, \\
c=336.20\end{array}$ \\
\hline Wavelength $(\AA)$ & 0.966 & 1.254 & 0.968 \\
\hline Beamline (ESRF) & ID30A1 & ID29 & ID29 \\
\hline No. Crystals & 1 & 1 & 1 \\
\hline $\begin{array}{l}\text { Resolution range (last } \\
\text { shell) }(\AA)\end{array}$ & $\begin{array}{l}\text { Isotropic } 3.56 \AA \\
\text { Ellipsoidal } 3.12 \AA \\
76.85 .0-3.12(3.32- \\
3.12)\end{array}$ & $\begin{array}{l}\text { Isotropic } 2.95 \AA \\
\text { Ellipsoidal } 2.42 \AA \\
127.1-2.42(2.69-2.42)\end{array}$ & $\begin{array}{l}\text { Ellipsoidal } 3.41 \AA \\
49.21-3.41(3.57-3.41)\end{array}$ \\
\hline $\begin{array}{l}\text { Completeness (last } \\
\text { shell) }(\%)\end{array}$ & $\begin{array}{l}\text { Overall } 73.1 \\
\text { Ellipsoidal: } 91.6(67.9)\end{array}$ & $\begin{array}{l}\text { Overall 61.4 } \\
\text { Ellipsoidal. } 89.1 \text { (64.0) }\end{array}$ & $\begin{array}{l}\text { Overall } 73.3 \\
\text { Ellipsoidal } 94.8 \text { (88.2) }\end{array}$ \\
\hline R-sym (last shell) & $0.128(1.30)$ & $0.112(0.618)$ & $0.283(1.873)$ \\
\hline R-meas (last shell) & $0.149(1.49)$ & $0.136(0.769)$ & $0.306(1.946)$ \\
\hline $\mathrm{I} / \sigma \mathrm{I}$ (last shell) & $8.0(1.7)$ & $7.7(1.9)$ & $7.7(1.5)$ \\
\hline CC(1/2) (last shell) & $0.994(0.536)$ & $0.992(0.630)$ & $0.995(0.696)$ \\
\hline $\begin{array}{l}\text { Redundancy (last } \\
\text { shell) }\end{array}$ & $3.9(3.9)$ & $3.0(2.5)$ & $14.1(14.6)$ \\
\hline \multicolumn{4}{|l|}{ Refinement } \\
\hline $\begin{array}{l}\text { Reflections (total) } \\
\text { For refinement: work } \\
\text { (free) }\end{array}$ & $\begin{array}{l}77848 \\
73897(3951)\end{array}$ & $\begin{array}{l}154519 \\
146946(7573)\end{array}$ & $\begin{array}{l}37875 \\
36023(1852)\end{array}$ \\
\hline R-work (last shell) & $0.240(0.369)$ & $0.223(0.328)$ & $0.220(0.313)$ \\
\hline R-free (last shell) & $0.273(0.397)$ & $0.257(0.257)$ & $0.273(0.358)$ \\
\hline $\begin{array}{l}\text { No of non-hydrogen } \\
\text { atoms }\end{array}$ & 18481 & 35955 & 19969 \\
\hline \multicolumn{4}{|l|}{ Validation } \\
\hline RMS(bonds) & 0.002 & 0.003 & 0.003 \\
\hline RMS(angles) & 1.170 & 1.198 & 1.207 \\
\hline $\begin{array}{l}\text { Average B-factor } \\
\left(\AA^{2}\right)\end{array}$ & 109.0 & 57.89 & 86.16 \\
\hline $\begin{array}{l}\text { Ramachandran } \\
\text { favored (\%) }\end{array}$ & 92.59 & 96.18 & 92.65 \\
\hline $\begin{array}{l}\text { Ramachandran } \\
\text { outliers (\%) }\end{array}$ & 0.32 & 0.09 & 0.79 \\
\hline Molprobity score & 1.50 & 1.76 & 1.96 \\
\hline Clash score & 1.20 & 2.74 & 2.83 \\
\hline
\end{tabular}




\section{Cells}

184 HEK-293T cells (purchased at ATCC, CRL-3216) were grown in complete Dulbecco's modified Eagle's medium (DMEM, Gibco) supplemented with 10\% fetal bovine serum (FBS) and 1\% penicillin-streptomycin. MDCK cells (provided by the National Influenza Center, Paris, France) were grown in Modified Eagle's medium (MEM, Gibco) supplemented with 5\% FBS and $1 \%$ penicillin-streptomycin.

\section{Plasmids}

191 The reverse genetics plasmids derived from the IAV A/WSN/33 (WSN) [40] and the IBV

192 B/Brisbane/60/2008 [41] were kindly provided by Pr. G. Brownlee (Sir William Dunn School

193 of Pathology, Oxford, UK) and Pr. D. Perez (College of Veterinary Medicine, University of

194 Georgia), respectively. For polymerase activity assays, a pPolI-Firefly plasmid encoding the

195 Firefly luciferase sequence in negative polarity flanked by the 5' and 3' non-coding regions of either the IAV or IBV NS segment was used. The pRenilla-TK plasmid (Promega) was used as

197 an internal control. The WSN pcDNA3.1-PB2, -PB1, -PA plasmids [32] and 198 B/Memphis/13/2003 (Memphis) pcDNA3.1-PB2, -PB1, -PA and -NP plasmids [42] were

199 described previously. The WSN-NP Open Reading Frame (ORF) was subcloned into the pCI200 plasmid. The WSN and Memphis pCI-PB2-G1 and pCI-PA-G1 plasmids used for Gaussia 201 luciferase complementation assays were constructed as described previously [43]. The RPB1 ORF was obtained from the Human ORFeome resource (hORFeome v3.1), fused to G2 at the N-terminus by PCR and subcloned into pcDNA3.1 (G2-RPB1). The CTD repeats 4 to 51 were 204 deleted from the G2-RPB1 construct by PCR (G2-RPB1 $\Delta$ CTD). The pCI-RPB2-G2 construct was kindly provided by Dr. B. Delmas (INRAE, Jouy-en-Josas). The wild-type full-length CTD sequences was fused at the C-terminus to an SV40 NLS by PCR using the G2-RPB1 plasmid as a template. The resulting amplicon was cloned in frame downstream the G2 sequence into 208 the pCI vector (G2-CTD). A sequence in which each CTD serine 5 residue was replaced by an 
alanine was ordered as synthetic gene (GenScript) and subcloned in place of the wild-type CTD

210 sequence into the G2-CTD construct (G2-CTD-S5A). The pCI-G2-NUP62 plasmid was

211 described previously [44]. Mutations were introduced by an adapted QuickChangeTM site-

212 directed mutagenesis (Agilent Technologies) protocol [45]. Primers and plasmid sequences are

213 available upon request.

\section{Protein complementation and minigenome assays}

216 HEK-293T cells were seeded in 96-well white opaque plates (Greiner Bio-One) the day before

217 transfection. For the split-luciferase complementation assays, cells were co-transfected in 218 technical triplicates with 25 ng plasmid encoding the polymerase subunits PB2, PB1 and PA 219 (either PB2-G1 or PA-G1, respectively) and $100 \mathrm{ng}$ of the G2-tagged targets (CTD, RPB1 or 220 RPB2, respectively) using polyethyleneimine (PEI-max, \#24765-1 Polysciences Inc). When 221 indicated, the CDK7 inhibitor BS-181-HC (Tocris Bioscience) was added 24 hours posttransfection (hpt) at a final concentration of $20 \mu \mathrm{M}$ for $1 \mathrm{~h}$. DMSO $0.2 \%$ was used as a control. under steady shaking $(650 \mathrm{rpm})$ and the Gaussia princeps luciferase enzymatic activity was measured on a Centro XS LB960 microplate luminometer (Berthold Technologies, reading time $10 \mathrm{~s}$ after injection of $50 \mu 1$ Renilla luciferase reagent (Promega). For the minigenome assays, cells were co-transfected in technical triplicates with $25 \mathrm{ng}$ of each pcDNA3.1 PB2, PB1, PA, in conjunction with 50, 10 and $5 \mathrm{ng}$ of the pCI-NP, pPolI-Firefly and pTK-Renilla plasmids, respectively. Luciferase activities were measured 20-24 hpt using the the Dual-Glo Luciferase Assay system (Promega) according to the manufacturer's instructions.

\section{Antibodies and immunoblots}

233 Total cell lysates were prepared in RIPA cell lysis buffer as described before [46]. Immunoblot 234 membranes were incubated with primary antibodies directed against CTD-pS5 (Active Motif, 
3EB), CTD-pS2 (Active Motif, 3E10), Gaussia princeps luciferase (New England Biolabs, \#E8023) or Tubulin (Sigma-Aldrich, B-5-1-2), and subsequently with the according HRPtagged secondary antibodies (Jackson Immunoresearch). Membranes were revealed with the

ECL2 substrate according to the manufacturer's instructions (Pierce) and chemiluminescence ImageLab (Bio-Rad).

\section{Production and characterisation of recombinant viruses}

243 The recombinant viruses were produced by transfection of a co-culture of HEK-293T and 244 MDCK cells as described previously [40,41]. The reverse genetics supernatants were titrated on MDCK cells in a standard plaque assay as described before [47]. Plaque diameters were 246 measured upon staining with crystal violet using Fiji [48].

\section{In vitro endonuclease and transcription activity assays}

249 RNA for the activity assays was produced in vitro with $\mathrm{T} 7$ polymerase. Recombinant 250 polymerases used corresponding to A/little yellow-shouldered bat/Guatemala/060/2010 and 251 B/Memphis/13/2003 were purified as previously described [42]. 23 nt RNA (5'-

252 GAAUCUAUACAUAAAGACCAGGC-3') was capped with vaccinia capping enzyme and 2'253 O-methyltransferase (NEB) and radiolabelled with $\left[\alpha^{32} \mathrm{P}\right]-\mathrm{GTP}$. For the endonuclease assay $25425 \mathrm{nM} \mathrm{FluPol}_{\mathrm{A}}$ and $50 \mathrm{nM} \mathrm{FluPol}_{\mathrm{B}}$ were incubated with 1.2-fold molar excess of v5' RNA $255\left(\right.$ FluPol $_{\mathrm{A}}:$ 5'-pAGUAGAAACAAGGC-3', FluPol $\mathrm{B}:$ 5'-pAGUAGUAACAAGAG-3') and the 256 capped RNA in reaction buffer containing $50 \mathrm{mM}$ HEPES $\mathrm{pH} 7.5,150 \mathrm{mM} \mathrm{NaCl}$, $2575 \mathrm{mM} \mathrm{MgCl}_{2}, 2 \mathrm{mM}$ tris(2-carboxyethyl)phosphine (TCEP). Transcription reactions were 258 performed with $50 \mathrm{nM} \mathrm{FluPol}{ }_{\mathrm{A}}$ or $\mathrm{FluPol}_{\mathrm{B}}$ in the reaction buffer, supplemented with $150 \mathrm{nM}$ 259 v3' template RNA (FluPol ${ }_{\mathrm{A}}:$ 5'-AGUUUGCCUGCUUCUGCU-3', FluPol ${ }_{\mathrm{B}}: \quad$ 5'- 
peptides were added at concentrations corresponding to at least a 10 -fold excess over the $\mathrm{K}_{\mathrm{D}}$ of

262 the lowest measured affinity for a two-repeat peptide. Two- and four-CTD repeat peptides were purchased from Covalab and six-repeat CTD peptide was synthesised at the Chemical Biology with RNA loading dye (formamide, $8 \mathrm{M}$ urea, $0.1 \% \mathrm{SDS}, 0.01 \%$ bromophenol blue (BPB), $0.01 \%$ xylene cyanol (XC)), supplemented with $50 \mathrm{mM}$ EDTA and boiled at $95{ }^{\circ} \mathrm{C}$. The reaction products were separated on $20 \%$ denaturing acrylamide gel (containing $8 \mathrm{M}$ urea) in Tris-Borate-EDTA (TBE) buffer, exposed on a Storage Phosphor screen and recorded with a Typhoon reader. DECADE ${ }^{\mathrm{TM}}$ marker was used as ladder.

\section{CTD sequences and alignment}

272 The RPB1 CTD domain amino acid sequences of Homo sapiens (NP_000928.1), Sus scrofa 273 (XP_020923484.1), Equus caballus (XP_014584045.2), Canis lupus (XP_038521325.1), and 274 Mus musculus (NP_001277997.1) host species were obtained from the RefSeq database [49]. 275 As the predicted RefSeq sequences available for the Gallus gallus (XP_040551262) and Anus 276 platyrhyncos (XM_038172734) RPB1 subunits were only partial, we designed a targeted 277 protein sequence assembly strategy data based on RNA-seq and/or WGS SRA public data 278 available for these two species. To obtain the Gallus gallus RPB1 complete sequence (1969 aa), 279 we first aligned Illumina RNA-seq short reads (ERR2664216) on the human RefSeq curated 280 protein sequence (NP_000928) using DIAMOND algorithm [50], and then used the aligned 281 reads for subsequent Trinity transcript assembly ("-longreads XP_040551262" option to use 282 the partial sequence as a guide) followed by Transdecoder for the ORF prediction [51]. The 283 Anus platyrhyncos RPB1 complete sequence (1970 aa) was obtained by aligning Illumina 284 RNA-seq short reads (SRR10176883) and PACBIO long reads (SRR8718129, SRR8718130) 285 on the JACEUL010000271.1 genomic scaffold by using respectively HISAT2 [52] and 286 minimap2 [53] followed by Stringtie2 [54] with the "-mix" option to allow hybrid de novo 
bioRxiv preprint doi: https://doi.org/10.1101/2022.02.04.479088; this version posted February 4, 2022. The copyright holder for this

preprint (which was not certified by peer review) is the author/funder, who has granted bioRxiv a license to display the preprint in perpetuity. It is made available under aCC-BY 4.0 International license.

287 gene assembly. The CTD sequences were aligned with SnapGene ${ }^{\circledR} 6.0$ and visualised by 288 Espript $3.0[55]$.

289 


\section{Results}

\section{1 \\ Cocrystal structures reveal distinct CTD binding sites in FluPol ${ }_{B}$ and FluPol $_{A}$}

292

Previous structural studies using a four repeat CTD pS5 peptide mimic (YSPTpSPS) 4 [32] revealed two distinct $\mathrm{CTD}$ binding sites on $\mathrm{FluPol}_{\mathrm{B}}$, denoted site $1 \mathrm{~B}$ and site $2 \mathrm{~B}$. Site $1 \mathrm{~B}$, exclusively on the PA subunit and in which the pS5 phosphate is bound by PA basic residues $\mathrm{K} 631$ and R634, is essentially the same as site 1A for bat influenza A polymerase [32] and is thereafter named site $1 \mathrm{AB}$. Site $2 \mathrm{~B}$, which extends across the PA-PB2 interface, is unique to FluPol $\mathrm{B}$ and distinct from site $2 \mathrm{~A}$ for $\mathrm{FluPol}_{\mathrm{A}}$, which is again exclusive to the PA subunit [32]. However, the original crystal structure data for FluPol $\mathrm{B}$ were of insufficient resolution to be able to construct a model for the CTD peptide in site $2 \mathrm{~B}$, nor even to define its directionality. To overcome this limitation, we co-crystallised the four repeat pS5 peptide with influenza B/Memphis/13/2003 polymerase in a different $P 2_{1}$ crystal form, previously used to obtain a structure with the $5^{\prime}$ end of the vRNA [35], and measured anisotropic diffraction data to a resolution of 2.42-2.95 $\AA$ (Table 1). The resultant map, which contains two heterotrimers in the asymmetric unit, showed clear electron density in site 2B for both trimers (Figure S1A), into which an unambiguous model for the CTD peptide could be built (Figure 1A and Figure S2A). Only very weak density for the CTD peptide is observed in site $1 \mathrm{AB}$, perhaps because of competition with a phosphate bound at the position of the phosphoserine. To reconfirm that sites $1 \mathrm{~B}$ and $2 \mathrm{~B}$ could be occupied simultaneously, we re-crystallised full promoter-bound FluPol${ }_{B}$ with the CTD peptide in the original $\mathrm{P}_{2} 21$ crystal form, but this time with a capped primer and at lower $\mathrm{pH}$. Under these conditions, the extremity of the vRNA $3^{\prime}$ end is in the RNA synthesis active site [56]. Anisotropic diffraction data to a resolution of 3.12-3.56 $\AA$ was measured and the resultant map showed clear electron density for the CTD peptide bound in both sites $1 \mathrm{AB}$ and $2 \mathrm{~B}$ (Figure 1B and Table 1), as reported previously for this crystal form [32] but with slightly improved resolution. Unexpectedly, the CTD peptides bound in site $1 \mathrm{AB}$ and site $2 \mathrm{~B}$ are orientated such that they cannot be linked by the shortest path, as this would be 
316 between both N-termini, which are $\sim 17 \AA$ apart, whereas the straight-line distance between the

317 C-ter of site $1 \mathrm{AB}$ and $\mathrm{N}$-ter of site $2 \mathrm{~B}$ is $\sim 36(44) \AA$. These distances suggest that a minimum

318 of 6, probably 7, heptad repeats would be required to occupy both sites contiguously (Figure

319 1B, dotted red line). This contrasts with the situation in $\mathrm{FluPol}_{\mathrm{A}}$, where the peptide

320 directionality in sites $1 \mathrm{AB}$ and $2 \mathrm{~A}$ allow them to be linked by the shortest path, implying that

321 four heptad repeats is sufficient to occupy both sites (Figure 1C) [32].

322 Three repeats (designated repeats $\mathrm{a}, \mathrm{b}$ and $\mathrm{c}$ ) of the CTD peptide (i.e.

323 Y1aS2aP3aT4apS5aP6aS7a-Y1bS2bP3bT4bpS5bP6bS7b-Y1cS2cP3cT4cpS5cP6c) are

324 visible in site $2 \mathrm{~B}$ in both structures, including two well-defined phosphoserines (in bold). The

325 N-terminal part of the CTD peptide (Y1a-S2b) forms a compact structure comprising two

326 successive proline turns stabilised by four intra-peptide hydrogen bonds, with P3a stacked on

327 Y1b and P6a stacked on PA/Y597 (Figure 1D). PB2 R132 partially stacks against the other

328 side of the Y1b sidechain, whose hydroxyl group hydrogen bonds to the main-chain of PB2

329 I135. The phosphate of pS5a forms a strong salt-bridge with PA R608 as well as hydrogen

330 bonding with S7a. FluPol${ }_{B}$-specific PA R608 is in a four-residue insertion (606-GDRV-609)

331 compared to $\mathrm{FluPol}_{\mathrm{A}}$, with hydrogen bond interactions from PA D607 and N611 positioning

332 the side-chain of PA Y597 under the CTD peptide. This configuration of residues seems

333 specifically designed to accommodate the compactly folded CTD peptide. Interestingly,

334 recently identified FluPol${ }_{B}-$ like polymerases from fish and amphibians [57] also possess the

335 four-residue insertion in PA. However, only in the Wuhan spiny-eel influenza virus polymerase,

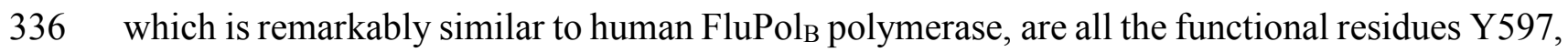

337 D607, R608, N611 conserved [57,58]. The rest of the CTD peptide (P3b-T4c) has an extended

338 conformation and lies across the PB2 627-domain (Figure 1D). To create the CTD binding

339 surface requires concerted side chain reorientations of PB2 W553, M572 and W575 (Figure

340 1D and Figure S2A), allowing P6b to pack on W553 and Y1c on M572 and L561, with its

341 hydroxyl group hydrogen bonding to D571. PB2 K556 forms a salt bridge with pS5b. 
342 Most functional studies on CTD are performed with human or avian influenza A polymerase,

343 whereas CTD binding has only been structurally characterised for bat A/little yellow-

344 shouldered bat/Guatemala/060/2010(H17N10) polymerase [32] and C/Johannesburg/1/1966

345 [33]. Although sequence alignments and mutational studies strongly suggest that the mode of

346 CTD binding is conserved for all IAV-like polymerase [32], we attempted to confirm this by

347 determining the structure of a CTD mimicking peptide bound to influenza A/Zhejiang/DTID-

348 ZJU01/2013(H7N9) polymerase. Previously, we have reported crystals of the A/H7N9 core

349 (PA 201-716, PB1 full-length, PB2 1-127) in the apo-state, which forms symmetrical dimers

350 as described elsewhere $[18,59,60]$. Here, we soaked the four-repeat pS5 CTD peptide mimic

351 into co-crystals of H7N9 core with the vRNA 5' hook. The crystals diffracted to a maximum

352 resolution of $3.41 \AA$ (Table 1) and again contain symmetrical dimers of the polymerase core.

353 We observed clear electron density, not only for the 5' hook, but also for the CTD peptide bound

354 in site 2A (Figure S1B and Figure S2B), essentially identically bound as previously seen for

355 bat influenza A/H17N10 polymerase (Figure S2B). However, there was no CTD peptide bound

356 in site $1 \mathrm{AB}$. The most likely explanation for this is that in the symmetrical dimeric form of

357 influenza A (core only, or full trimer), both polymerases are in the so-called 'dislocated'

358 conformation [18] with an open active site. In particular, PA regions 425-452 and 586-618 are

359 rotated by $\sim 20^{\circ}$, compared to the active, monomeric promoter bound state (e.g. A/H3N2

360 polymerase structure, [59], PDB:6RR7). This particularly affects the position of key site $1 \mathrm{AB}$

361 binding site residues Y445, E449 and F612 (Figure S2C), thus preventing CTD at this site,

362 while not affecting binding to site $2 \mathrm{~A}$.

363 A sequence alignment of the $\mathrm{CTD}$ binding sites $1 \mathrm{AB}, 2 \mathrm{~A}$, and $2 \mathrm{~B}$ from the representative

364 influenza A and B viruses used hereinafter is shown in Figure 1E (sequence alignments of the

365 full-length PB2, PA and PB1 subunit are provided in Figure S3). Key residues for CTD binding

366 are mostly conserved (dark and light blue) in site $1 \mathrm{AB}$, non-conserved in site $2 \mathrm{~A}$ and partially

367 conserved in site $2 B$. 
The FluPol-CTD interaction can be monitored using a cell-based luciferase

To confirm the structural findings of this study and investigate the distinctive features of CTD

372 binding sites in $\mathrm{FluPol}_{\mathrm{B}}$ and $\mathrm{FluPol}_{\mathrm{A}}$ in the cellular context, we set up a CTD-binding assay using the Gaussia princeps luciferase trans-complementing fragments (G1 and G2) [43]. The full-length CTD was fused to G2 and the SV40 nuclear localization signal (G2-CTD). PB2 or PA were fused to G1 at their C-terminus (PB2-G1 and PA-G1, respectively, schematically represented in red in Figure 2A and 2B) as FluPol was shown to retain activity when tagged at these sites [44]. Upon co-expression of G2-CTD and the three polymerase subunits (including PB2-G1 or PA-G1), a luminescence signal resulting from the FluPol-CTD interaction was

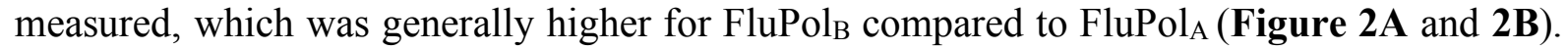

380 The interaction signal decreased when PB1 was omitted, in agreement with previous reports that the FluPol-CTD interaction depends on FluPol assembly [28], and it was independent of

382 FluPol catalytic activity (Figure 2A and 2B, PB1 D444A-D445A mutant [61]). When key CTD-contacting residues of FluPol$A$ were mutated (PA K289A and R638A [32]), the 384 interaction signal was significantly decreased compared to PA wt (Figure 2C and 2D). To test 385 whether the FluPol-CTD binding assay reflects the dependency on the phosphorylation of the 386 CTD S5 moiety, all S5 residues of the CTD were mutated to alanine (schematically represented 387 in Figure 2E), which prevented S5 phosphorylation as documented by western blot (Figure 2F and $\mathbf{G}$, bottom). Although the wt and S5A CTD showed similar steady-state levels of 389 expression, the binding of the S5A CTD to FluPol ${ }_{B}$ and FluPol $_{\mathrm{A}}$ was significantly decreased 390 compared to WT CTD. Consistently, pharmacological inhibition of CDK7, which represents 391 the major kinase for CTD S5 phosphorylation [62], specifically reduced FluPol $\mathrm{A} / \mathrm{B}_{\mathrm{B}}$ binding to 
these data demonstrate that the FluPol-CTD interaction can be accurately monitored in cells

394 using our split-luciferase complementation assay conditions.

Structure-driven mutagenesis confirms FluPol ${ }_{B}$ and FluPol $_{A}$ have distinct CTD binding

modes on PA

To systematically assess in vivo FluPol-CTD binding, we mutated key residues forming the

CTD binding sites in the FluPol${ }_{\mathrm{B}}$ and/or FluPol${ }_{\mathrm{A}}$ co-crystal structures and measured the impact of these mutations on CTD-binding using the split-luciferase complementation assay described above (Figure 2). In parallel, we investigated polymerase activity in a minireplicon assay, and we rescued recombinant mutant IBVs and IAVs and measured plaque diameters on reverse genetic supernatants as a read-out for viral growth capacity. The FluPol A $_{\text {residue nature and }}$ numbering is used in the text and figures, except when indicated.

The structure and key residues of the CTD binding site $1 \mathrm{AB}$ are conserved between FluPolB and $\mathrm{FluPol}_{\mathrm{A}}$ (Figure 1E and Figure 3A). We mutated the pS5 interacting residues PA K635 and R638 to alanines. The mutations did not affect PA accumulation levels (Figure 3B) but significantly decreased in vivo binding to the full-length CTD for both $\mathrm{FluPol}_{\mathrm{B}}$ and $\mathrm{FluPol}_{\mathrm{A}}$

(Figure 3C and Figure S5A), which is in line with biochemical data obtained in vitro with CTD-mimicking peptides [32]. Consistently, the corresponding recombinant mutant IBVs and 411 IAVs were attenuated or could not be rescued (Figure 3D). Noteworthy, the impact of site $1 \mathrm{AB}$ 412 mutations on the viral phenotype and FluPol activity was generally lower for IBV than IAV 413 mutants (Figure 3D and 3E) although the defect in CTD binding was more pronounced for 414 FluPol $_{\mathrm{B}}$ (Figure 3C), suggesting that FluPol $\mathrm{B}$ activity is less reliant on CTD binding at site 415 1AB.

416 CTD binding site 2A differs substantially between FluPol $\mathrm{B}$ and $\mathrm{FluPol}_{\mathrm{A}}$ (Figure 1E and Figure 417 4A). We introduced mutations at residues PA K289, R454 and S420, which are critical for CTD 
418 binding to $\mathrm{FluPol}_{\mathrm{A}}$ and are not conserved in $\mathrm{FluPol}_{\mathrm{B}}$, and we deleted the PA 550 loop, which

419 buttresses the CTD in FluPol $_{\mathrm{A}}$ and is considerably shortened in FluPol . These modifications

420 did not affect PA accumulation levels (Figure 4B) and specifically decreased in vivo CTD

421 binding of FluPol$_{\mathrm{A}}$ but not FluPol (Figure 4C and Figure S5B). Consistently, the PA R454A

422 and S420E mutations in the IBV background (IBV numbering: K450A and K416E) did not

423 impair viral growth (Figure 4D) nor did PA K450A affect FluPol B $_{\mathrm{B}}$ polymerase activity (Figure

424 4E). The PA S420E and PA 550 loop deletion impaired FluPol B $_{\mathrm{B}}$ activity (Figure 4E), indicating

425 that they hinder a function of the polymerase besides CTD binding.

\section{The PB2 627 domain is involved in CTD binding for FluPol ${ }_{B}$ but not FluPol}

The key CTD binding residues and the $3 \mathrm{D}$ structure of site $2 \mathrm{~B}$ are often conserved between

FluPol ${ }_{\mathrm{B}}$ and $\mathrm{FluPol}_{\mathrm{A}}($ Figure 1E and Figure 5A). However, CTD binding at site $2 \mathrm{~B}$ has never

been observed in vitro with FluPol , and the inserted PA 608 loop (IBV numbering) which

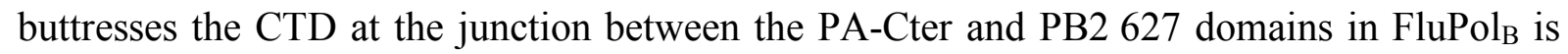
absent in FluPol A $_{\text {. The PA R608A mutation significantly decreased FluPol }}$ CTD binding in our cell-based complementation assay (Figure 5B middle panel, no counterpart residue in

$\mathrm{FluPol}_{\mathrm{A}}$ ). Consistently, the corresponding recombinant mutant IBV could not be rescued upon reverse genetics (Figure S6), and the PA R608 mutant FluPol B $_{\mathrm{B}}$ showed reduced polymerase activity (Figure 5B, right panel). We then mutated to alanines the residues W552 and R555 (W553 and R556 according to IBV numbering), which are located on the PB2 627 domain,

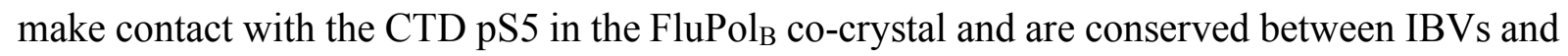
IAVs (Figure 1E and Figure 5A). The mutations did not affect PB2 accumulation levels

440 (Figure 5C) and either decreased (R555A) or increased (W552A) CTD binding of FluPol ${ }_{\mathrm{B}}$, 441 whereas they had no effect on FluPol $_{\mathrm{A}}$ CTD binding (Figure 5D and Figure S5C). To rule out any CTD binding activity on the FluPol A PB2 627 domain, we deleted the whole domain as 
444 but not to $\mathrm{FluPol}_{\mathrm{A}}$ (Figure 5E). Nevertheless, single amino acid substitutions at residues PB2

445 W552 and R555 impaired viral growth and polymerase activity of FluPol $\mathrm{B}$ as well as FluPol${ }_{\mathrm{A}}$, 446 however with weaker effects on $\mathrm{FluPol}_{\mathrm{A}}$ (Figure $\mathbf{5 F}$ and $\mathbf{5 G}$ ). Given the multiple functions 447 attributed to the PB2 627 domain [63], the most likely interpretation of our data is that residues 448 on the PB2 627 domain contribute to the CTD recruitment exclusively for IBVs while they 449 have overlapping CTD-unrelated functions for IBVs and IAVs.

450 We asked whether this major difference between FluPol$_{\mathrm{B}}$ and $\mathrm{FluPol}_{\mathrm{A}} \mathrm{CTD}$ binding modes 451 results in different levels of transcriptional activation by CTD mimicking peptides in vitro. A 452 model has been proposed for FluPol $\mathrm{C}_{\mathrm{C}}$ in which the CTD stabilizes a transcription-competent conformation by binding at the interface of PB1, P3 (PA equivalent), and the flexible PB2 Cterminus [33]. Our observations suggest that the same model could apply to FluPol${ }_{B}$ and not to FluPol${ }_{\mathrm{A}}$. Therefore, we tested the impact of pS5 CTD mimicking peptides of varying lengths (two, four, or six YSPTSPS repeats) on FluPol $_{\mathrm{B}}$ and $\mathrm{FluPol}_{\mathrm{A}}$ in vitro transcriptional activity (Figure 6A). The FluPol ${ }_{\mathrm{B}}$ in vitro endonuclease activity (Figure 6A, lane 4) and elongation mimicking peptide, and a similar trend was observed with $\mathrm{FluPol}_{\mathrm{A}}$ (Figure 6B, lanes 4 and 8). These data complement previous reports that CTD pS5 binding facilitates FluPol${ }_{\mathrm{A}}$ and FluPol$_{\mathrm{C}}$ transcriptional activity [33] and strengthen the hypothesis that the CTD stabilises FluPol in a transcription-competent conformation [20]. However, our finding that the FluPol${ }_{\mathrm{A}}$ PB2 627

463 domain has no CTD binding activity (Figure 5G) indicates that FluPol $_{\mathrm{A}}$ has evolved a 464 divergent mechanism by which the CTD stabilizes the FluPol transcriptase. It also questions 465 whether bridging of the PB2 627 and PA-Cter domains per se is needed for transcriptional 466 activation of FluPols. 
The RNAP II transcriptional machinery is highly conserved across eukaryotes, and the CTD in particular shows almost no sequence differences among vertebrate (mammalian and avian) host species susceptible to IAV or IBV infection (Figure S7). It is therefore unlikely that differences

472 in the CTD amino acid sequence drove the evolution of divergent IBV and IAV CTD-binding 473 modes. We investigated whether $\mathrm{FluPol}_{\mathrm{A} / \mathrm{B}}$ can interact with the two major RNAP II subunits 474 (RPB1, RPB2) independently of the CTD, using the split-gaussia luciferase complementation 475 assay. The G2-RPB1 and RPB2-G2 fusion proteins were co-expressed with G1-tagged FluPol 476 (PA-G1) by transient transfection as described above. Both combinations resulted in robust and 477 comparable interaction signals (Figure 7A). Interestingly, in the presence of a truncated RPB1 478 deleted from the CTD (RPB1 $\triangle \mathrm{CTD})$, a stable interaction signal with FluPol $\mathrm{A}_{\mathrm{A}} \mathrm{B}$ could still be 479 measured. Mutations in site 1A/B which reduced CTD binding to background levels (Figure 480 3C) had only weak effects on RPB1 and RPB1 $\triangle$ CTD binding (PA K631A R635 in Figure 7B, 481 PA K635A R638 in Figure 7C). The same was observed with site 2A mutations (PA K450A 482 in Figure 7B, PA R454A in Figure 7C) and site 2B mutations and (PB2 R555A Figure 7B, 483 PB2 K556A in Figure 7C). These findings, taken together with the relatively low affinity of 484 FluPol for pS5 CTD peptides [32], suggest that the CTD is not the only interface between 485 FluPol and the host RNAP II, and it may not be essential to connect FluPol to the RNAP II but 486 rather to coordinate FluPol cap-snatching. 


\section{Discussion}

489

490

491

492

Here we report co-crystal structures of a human FluPol${ }_{\mathrm{B}}$ and an avian (isolated from human) FluPol $\mathrm{A}_{\mathrm{A}}$ bound to pS5 CTD mimicking peptides. We uncover the conformation and directionality of the CTD peptide bound to FluPol $\mathrm{B}$ at a site that crosses over from the PA-Cter to the PB2 627 domain (site 2B), and has no counterpart on FluPol$A$ or FluPolc. Two CTD binding sites have been characterised on $\mathrm{FluPol}_{\mathrm{A}}$ (sites $1 \mathrm{~A}$ and $\left.2 \mathrm{~A}\right)([32]$ and this study) and on FluPol $_{\mathrm{C}}$ (sites $1 \mathrm{C}$ and 2C, distinct from sites $1 \mathrm{~A}$ and 2A) [33]. On the FluPol ${ }_{\mathrm{B}}$ co-crystal structure, site $1 \mathrm{~B}$ is similar to site $1 \mathrm{~A}$, whereas site $2 \mathrm{~B}$ is distinct from site $2 \mathrm{~A}$ and $2 \mathrm{C}$.

By performing structure-based mutagenesis of $\mathrm{FluPol}_{\mathrm{B}}$ and $\mathrm{FluPol}_{\mathrm{A}}$ followed by a systematic investigation of FluPol-CTD binding, FluPol transcription/replication activity and viral phenotype, we confirm that CTD binding involves the same key residues at site $1 \mathrm{AB}$ for $\mathrm{FluPol}_{\mathrm{B}}$ and $\mathrm{FluPol}_{\mathrm{A}}$, but distinct and specific residues at site $2 \mathrm{~A}$ for $\mathrm{FluPol}_{\mathrm{A}}$ and site $2 \mathrm{~B}$ for FluPolB, respectively. In particular, we demonstrate that the PA 606-609 loop, which buttresses the CTD at the junction between PA and PB2 in the FluPol ${ }_{\mathrm{B}}$ co-crystal structure and is not conserved in $\mathrm{FluPol}_{\mathrm{A}}$ or FluPol $\mathrm{C}$, is an essential component of site 2B.

Our data and others' $[32,33]$ demonstrate that IAVs, IBVs and ICVs have evolved divergent CTD binding modes, and raise questions about the driving force behind this divergent evolution. Large-scale meta-transcriptomic approaches have identified IBV-like and IDV-like viruses in fish and amphibians, suggesting that the influenza viruses of all four genera might be distributed among a much wider range of vertebrate species than recognised so far [57,58]. Phylogenetic analyses, although limited by strong sampling biases across species, indicate that both virushost co-divergence over long timescales and cross-species transmissions have shaped the evolution of influenza viruses. With one of the two CTD binding sites being conserved between IAVs and IBVs but absent in ICVs, the divergence of the bipartite CTD binding mode apparently matches the evolutionary distance between the three types of influenza viruses [64]. Interestingly however, we demonstrate that, in contrast to what is observed for IBVs and ICVs 
514 ([32,33] and this study), the PB2 627 domain is not involved in CTD binding for IAVs.

515 Therefore, from a mechanistic point of view, the CTD-dependent transcriptional activation of

516 FluPol might be closer between IBVs and ICVs than between IBVs and IAVs as a consequence

517 of a distinctive evolutionary pressure exerted on IAVs. The FluPol${ }_{\mathrm{A}}$ CTD binding mode

518 presumably reflects an avian-optimised mode and co-evolved with protein interfaces between

519 avian host factors and the PB2 627 domain, known to restrict avian IAV replication in humans

520 (the principal hosts of IBVs and ICVs).

521 Another example of a functional interaction with RNAP II being achieved through distinct CTD

522 binding is provided by the cellular mRNA capping enzyme (CE). The CEs from

Schizosaccharomyces pombe, Candida albicans and Mus musculus were shown to bind directly

S5 CTD repeats with very distinct binding interfaces and distinct conformations of the bound

CTD [65]. These distantly related species show major differences in the CTD length and sequence [26] which could at least partially account for the divergence in CE-CTD binding modes. In contrast, the CTD is highly conserved among host species susceptible to IAV, IBV and ICV infections (Figure S7).

There is considerable evidence, however, that the FluPol-CTD interaction is only part of a more complex interaction pattern between the viral and cellular transcription machineries, raising the 531 possibility that interactions between the FluPol and less conserved components of the cellular transcriptional machinery could have indirectly shaped the evolution of distinct CTD binding modes. We observed that a truncated RPB1 subunit, which lacks the CTD, retains partial

534 binding to FluPol (Figure 7). Mass-spectrometry screenings have identified other RNAP II 535 subunits and multiple transcriptional pausing and elongation factors as potential FluPol 536 interaction partners [31]. Host factors involved in transcription such as DDX17 were found to 537 bind FluPol and to determine IAV host-specificity [66]. By analogy, CEs not only bind to the pS5 CTD but also to the transcription pausing DRB Sensitivity-Inducing Factor (DSIF) [65] and make additional direct interactions with the nascent transcript exit site on the body of 
RNAP II [67]. Likewise, it was shown recently that the integrator complex binds RNAP II in

541 its promotor-proximal paused state through direct interactions with the CTD of RPB1 but also

542 with RPB2, RPB3, and RPB11, and through indirect interaction with the negative elongation

543 factor NELF and DSIF [68]. Intriguingly, FluPol was also found to interact with the DSIF

544 subunit SPT5 [69]. To what extent host-specific features of SPT5 or other cellular factors may

545 have constrained the evolution of CTD-binding sites on FluPol remains to be explored.

546 We show that the in vitro transcriptional activity of $\mathrm{FluPol}_{\mathrm{B}}$ is facilitated by the addition of

547 CTD pS5 mimicking peptides, as reported previously for $\mathrm{FluPol}_{\mathrm{A}}$ and $\mathrm{FluPol}_{\mathrm{C}}$ [33]. The

548 mechanism previously proposed for FluPolc $[20,33]$ in which the CTD stabilises FluPol in a

549 transcription-competent conformation by bridging P3 (the PA equivalent for ICVs) and PB2,

550 could possibly apply to FluPol $\mathrm{B}_{\mathrm{B}}$ with PA-PB2 bridging occurring at site $2 \mathrm{~B}$. Our data show that

551 it does not apply to $\mathrm{FluPol}_{\mathrm{A}}$, unless another yet unidentified domain of PB2, distinct from the

552 PB2 627 domain, is involved.

553 As underlined by the different sensitivity of IAV and IBVs to cap-binding inhibitors related to

554 differences in the cap-binding mode of their PB2 subunits [70], a detailed understanding of

555 structural and functional differences between FluPol$_{\mathrm{A}}$ and $\mathrm{FluPol}_{\mathrm{B}}$ is of significant importance

556 with regard to the development of broad-spectrum antivirals and need to be taken into account

557 when targeting the FluPol-CTD binding interface for antiviral intervention. 


\section{Acknowledgments}

560 We thank Pr. Daniel Perez (University of Georgia), Dr. Bernard Delmas (INRAE) and Dr. Yves Janin (Institut Pasteur) for sharing material and reagents, and Dr. Yves Jacob for helpful discussions.

\section{Funding sources}

565 This work was funded by the ANR grant FluTranscript (ANR-18-CE18-0028), holded jointly 566 by SC and NN. TK was funded by the ANR grants Flutranscript ANR-18-CE18-0028 and Labex IBEID ANR-10-LABX-62-IBEID.

\section{References}

1. Krammer F, Smith GJD, Fouchier RAM, Peiris M, Kedzierska K, Doherty PC, et al. Influenza. Nat Rev Dis Prim. 2018;4: 3. doi:10.1038/s41572-018-0002-y

2. Caini S, Kroneman M, Wiegers T, El Guerche-Séblain C, Paget J. Clinical characteristics and severity of influenza infections by virus type, subtype, and lineage: A systematic literature review. Influenza Other Respi Viruses. 2018;12: 780-792. doi:10.1111/IRV.12575

3. Zaraket H, Hurt AC, Clinch B, Barr I, Lee N. Burden of influenza B virus infection and considerations for clinical management. Antiviral Res. 2021;185. doi:10.1016/J.ANTIVIRAL.2020.104970

4. Yoon SW, Webby RJ, Webster RG. Evolution and ecology of influenza A viruses. Curr Top Microbiol Immunol. 2014;385: 359-375. doi:10.1007/82_2014_396

5. Suzuki Y, Nei M. Origin and evolution of influenza virus hemagglutinin genes. Mol Biol Evol. 2002;19: 501-509. doi:10.1093/OXFORDJOURNALS.MOLBEV.A004105

6. Parry R, Wille M, Turnbull OMH, Geoghegan JL, Holmes EC. Divergent Influenza-Like Viruses of Amphibians and Fish Support an Ancient Evolutionary Association. Viruses. 2020;12. doi:10.3390/V12091042

7. Baker SF, Nogales A, Finch C, Tuffy KM, Domm W, Perez DR, et al. Influenza A and B virus intertypic reassortment through compatible viral packaging signals. J Virol. 2014;88: 1077810791. doi:10.1128/JVI.01440-14

8. Eisfeld AJ, Neumann G, Kawaoka Y. At the centre: influenza A virus ribonucleoproteins. Nat Rev Microbiol. 2015;13: 28-41. doi:10.1038/nrmicro3367

9. Coloma R, Arranz R, de la Rosa-Trevín JM, Sorzano COS, Munier S, Carlero D, et al. Structural insights into influenza A virus ribonucleoproteins reveal a processive helical track as transcription mechanism. Nat Microbiol. 2020;5: 727-734. doi:10.1038/s41564-020-0675-3

10. Moeller A, Kirchdoerfer RN, Potter CS, Carragher B, Wilson IA. Organization of the influenza virus replication machinery. Science. 2012;338: 1631-1634. doi:10.1126/SCIENCE.1227270

11. Arranz R, Coloma R, Chichón FJ, Conesa JJ, Carrascosa JL, Valpuesta JM, et al. The structure of native influenza virion ribonucleoproteins. Science. 2012;338: 1634-1637. doi:10.1126/SCIENCE.1228172

12. Wandzik JM, Kouba T, Cusack S. Structure and Function of Influenza Polymerase. Cold Spring Harb Perspect Med. 2021;11. doi:10.1101/CSHPERSPECT.A038372

13. Deng T, Vreede FT, Brownlee GG. Different de novo initiation strategies are used by influenza virus RNA polymerase on its cRNA and viral RNA promoters during viral RNA replication. J Virol. 2006;80: 2337-48. doi:10.1128/JVI.80.5.2337-2348.2006

14. Oymans J, Te Velthuis AJW. A Mechanism for Priming and Realignment during Influenza A 
Virus Replication. J Virol. 2018;92. doi:10.1128/JVI.01773-17

15. Plotch SJ, Bouloy M, Krug RM. Transfer of 5'-terminal cap of globin mRNA to influenza viral complementary RNA during transcription in vitro. Proc Natl Acad Sci U S A. 1979;76: 1618 22. doi:10.1073/pnas.76.4.1618

16. Bouloy M, Plotch SJ, Krug RM. Both the 7-methyl and the 2'-O-methyl groups in the cap of mRNA strongly influence its ability to act as primer for influenza virus RNA transcription. Proc Natl Acad Sci U S A. 1980;77: 3952-6. doi:10.1073/pnas.77.7.3952

17. Poon LL, Pritlove DC, Fodor E, Brownlee GG. Direct evidence that the poly(A) tail of influenza A virus mRNA is synthesized by reiterative copying of a $U$ track in the virion RNA template. J Virol. 1999;73: 3473-6. doi:10.1128/JVI.73.4.3473-3476.1999

18. Wandzik JM, Kouba T, Karuppasamy M, Pflug A, Drncova P, Provaznik J, et al. A StructureBased Model for the Complete Transcription Cycle of Influenza Polymerase. Cell. 2020;181: 877-893.e21. doi:10.1016/j.cell.2020.03.061

19. Bouloy M, Plotch SJ, Krug RM. Globin mRNAs are primers for the transcription of influenza viral RNA in vitro. Proc Natl Acad Sci U S A. 1978;75: 4886-90. doi:10.1073/pnas.75.10.4886

20. Walker AP, Fodor E. Interplay between Influenza Virus and the Host RNA Polymerase II Transcriptional Machinery. Trends Microbiol. 2019;27: 398-407. doi:10.1016/j.tim.2018.12.013

21. Dias A, Bouvier D, Crépin T, McCarthy AA, Hart DJ, Baudin F, et al. The cap-snatching endonuclease of influenza virus polymerase resides in the PA subunit. Nature. 2009;458: 914 8. doi:10.1038/nature07745

22. Kouba T, Drncová $P$, Cusack S. Structural snapshots of actively transcribing influenza polymerase. Nat Struct Mol Biol. 2019;26: 460-470. doi:10.1038/s41594-019-0232-z

23. Worch R, Niedzwiecka A, Stepinski J, Mazza C, Jankowska-Anyszka M, Darzynkiewicz E, et al. Specificity of recognition of mRNA 5' cap by human nuclear cap-binding complex. RNA. 2005;11: 1355-63. doi:10.1261/rna.2850705

24. Cramer P, Bushnell DA, Kornberg RD. Structural basis of transcription: RNA polymerase II at 2.8 angstrom resolution. Science. 2001;292: 1863-1876. doi:10.1126/SCIENCE.1059493

25. Schüller R, Forné I, Straub T, Schreieck A, Texier Y, Shah N, et al. Heptad-Specific Phosphorylation of RNA Polymerase II CTD. Mol Cell. 2016;61: 305-14. doi:10.1016/j.molcel.2015.12.003

26. Eick D, Geyer M. The RNA polymerase II carboxy-terminal domain (CTD) code. Chem Rev. 2013;113: 8456-90. doi:10.1021/cr400071f

27. Martínez-Alonso M, Hengrung N, Fodor E. RNA-Free and Ribonucleoprotein-Associated Influenza Virus Polymerases Directly Bind the Serine-5-Phosphorylated Carboxyl-Terminal Domain of Host RNA Polymerase II. J Virol. 2016;90: 6014-6021. doi:10.1128/JVI.00494-16

28. Engelhardt OG, Smith M, Fodor E. Association of the influenza A virus RNA-dependent RNA polymerase with cellular RNA polymerase II. J Virol. 2005;79: 5812-8. doi:10.1128/JVI.79.9.5812-5818.2005

29. Vos SM, Farnung L, Urlaub H, Cramer P. Structure of paused transcription complex Pol IIDSIF-NELF. Nature. 2018;560: 601-606. doi:10.1038/s41586-018-0442-2

30. Chan AY, Vreede FT, Smith M, Engelhardt OG, Fodor E. Influenza virus inhibits RNA polymerase II elongation. Virology. 2006;351: 210-7. doi:10.1016/j.virol.2006.03.005

31. Krischuns T, Lukarska M, Naffakh N, Cusack S. Influenza Virus RNA-Dependent RNA Polymerase and the Host Transcriptional Apparatus. Annu Rev Biochem. 2021;90: 321-348. doi:10.1146/ANNUREV-BIOCHEM-072820-100645

32. Lukarska M, Fournier G, Pflug A, Resa-Infante P, Reich S, Naffakh N, et al. Structural basis of an essential interaction between influenza polymerase and Pol II CTD. Nature. 2017;541: 117121. doi:10.1038/nature20594

33. Serna Martin I, Hengrung N, Renner M, Sharps J, Martínez-Alonso M, Masiulis S, et al. A Mechanism for the Activation of the Influenza Virus Transcriptase. Mol Cell. 2018;70: 11011110.e4. doi:10.1016/j.molcel.2018.05.011 
34. McCoy AJ, Grosse-Kunstleve RW, Adams PD, Winn MD, Storoni LC, Read RJ. Phaser

660

661

662

663

664

665

666

667

668

669

670

671

672

673

674

675

676

677

678

679

680

681

682

683

684

685

686

687

688

689

690

691

692

693

694

695

696

697

698

699

700

701

702

703

704

705

706

707 crystallographic software. J Appl Crystallogr. 2007;40: 658-674. doi:10.1107/S0021889807021206

35. Thierry E, Guilligay D, Kosinski J, Bock T, Gaudon S, Round A, et al. Influenza Polymerase Can Adopt an Alternative Configuration Involving a Radical Repacking of PB2 Domains. Mol Cell. 2016;61: 125-37. doi:10.1016/j.molcel.2015.11.016

36. Emsley P, Cowtan K. Coot: model-building tools for molecular graphics. Acta Crystallogr D Biol Crystallogr. 2004;60: 2126-2132. doi:10.1107/S0907444904019158

37. Murshudov GN, Vagin AA, Dodson EJ. Refinement of macromolecular structures by the maximum-likelihood method. Acta Crystallogr D Biol Crystallogr. 1997;53: 240-255. doi:10.1107/S0907444996012255

38. Chen VB, Arendall WB, Headd JJ, Keedy DA, Immormino RM, Kapral GJ, et al. MolProbity: all-atom structure validation for macromolecular crystallography. Acta Crystallogr D Biol Crystallogr. 2010;66: 12-21. doi:10.1107/S0907444909042073

39. Wandzik JM, Kouba T, Cusack S. Structure and Function of Influenza Polymerase. Cold Spring Harb Perspect Med. 2020; a038372. doi:10.1101/cshperspect.a038372

40. Fodor E, Devenish L, Engelhardt OG, Palese P, Brownlee GG, García-Sastre A. Rescue of influenza A virus from recombinant DNA. J Virol. 1999;73: 9679-9682. doi:10.1128/JVI.73.11.9679-9682.1999

41. Nogales A, Perez DR, Santos J, Finch C, Martínez-Sobrido L. Reverse Genetics of Influenza B Viruses. Methods Mol Biol. 2017;1602: 205-238. doi:10.1007/978-1-4939-6964-7_14

42. Reich S, Guilligay D, Pflug A, Malet H, Berger I, Crépin T, et al. Structural insight into capsnatching and RNA synthesis by influenza polymerase. Nature. 2014;516: 361-6. doi:10.1038/nature14009

43. Cassonnet P, Rolloy C, Neveu G, Vidalain PO, Chantier T, Pellet J, et al. Benchmarking a luciferase complementation assay for detecting protein complexes. Nat Methods. 2011;8: 990992. doi:10.1038/NMETH.1773

44. Munier S, Rolland T, Diot C, Jacob Y, Naffakh N. Exploration of Binary Virus-Host Interactions Using an Infectious Protein Complementation Assay. Mol Cell Proteomics. 2013;12: 2845. doi:10.1074/MCP.M113.028688

45. Zheng L, Baumann U, Reymond JL. An efficient one-step site-directed and site-saturation mutagenesis protocol. Nucleic Acids Res. 2004;32. doi:10.1093/NAR/GNH110

46. Krischuns T, Günl F, Henschel L, Binder M, Willemsen J, Schloer S, et al. Phosphorylation of TRIM28 Enhances the Expression of IFN- $\beta$ and Proinflammatory Cytokines During HPAIV Infection of Human Lung Epithelial Cells. Front Immunol. 2018;9: 2229. doi:10.3389/fimmu.2018.02229

47. Matrosovich M, Matrosovich T, Garten W, Klenk HD. New low-viscosity overlay medium for viral plaque assays. Virol J. 2006;3. doi:10.1186/1743-422X-3-63

48. Schindelin J, Arganda-Carreras I, Frise E, Kaynig V, Longair M, Pietzsch T, et al. Fiji: an open-source platform for biological-image analysis. Nat Methods. 2012;9: 676-682. doi:10.1038/NMETH.2019

49. O'Leary NA, Wright MW, Brister JR, Ciufo S, Haddad D, McVeigh R, et al. Reference sequence (RefSeq) database at NCBI: current status, taxonomic expansion, and functional annotation. Nucleic Acids Res. 2016;44: D733-D745. doi:10.1093/NAR/GKV1189

50. Buchfink B, Reuter K, Drost HG. Sensitive protein alignments at tree-of-life scale using DIAMOND. Nat Methods. 2021;18: 366-368. doi:10.1038/S41592-021-01101-X

51. Grabherr MG, Haas BJ, Yassour M, Levin JZ, Thompson DA, Amit I, et al. Full-length transcriptome assembly from RNA-Seq data without a reference genome. Nat Biotechnol. 2011;29: 644-652. doi:10.1038/NBT.1883

52. Kim D, Paggi JM, Park C, Bennett C, Salzberg SL. Graph-based genome alignment and genotyping with HISAT2 and HISAT-genotype. Nat Biotechnol. 2019;37: 907-915. doi:10.1038/S41587-019-0201-4

53. Li H. Minimap2: pairwise alignment for nucleotide sequences. Bioinformatics. 2018;34: 3094- 
54. Kovaka S, Zimin A V., Pertea GM, Razaghi R, Salzberg SL, Pertea M. Transcriptome assembly from long-read RNA-seq alignments with StringTie2. Genome Biol. 2019;20. doi:10.1186/S13059-019-1910-1

55. Robert X, Gouet P. Deciphering key features in protein structures with the new ENDscript server. Nucleic Acids Res. 2014;42. doi:10.1093/NAR/GKU316

56. Reich S, Guilligay D, Cusack S. An in vitro fluorescence based study of initiation of RNA synthesis by influenza B polymerase. Nucleic Acids Res. 2017;45: 3353-3368. doi:10.1093/NAR/GKX043

57. Shi M, Lin XD, Chen X, Tian JH, Chen LJ, Li K, et al. The evolutionary history of vertebrate RNA viruses. Nature. 2018;556: 197-202. doi:10.1038/S41586-018-0012-7

58. Parry R, Wille M, Turnbull OMH, Geoghegan JL, Holmes EC. Divergent Influenza-Like Viruses of Amphibians and Fish Support an Ancient Evolutionary Association. Viruses. 2020;12. doi:10.3390/V12091042

59. Fan H, Walker AP, Carrique L, Keown JR, Serna Martin I, Karia D, et al. Structures of influenza A virus RNA polymerase offer insight into viral genome replication. Nature. 2019;573: 287-290. doi:10.1038/s41586-019-1530-7

60. Chang S, Sun D, Liang H, Wang J, Li J, Guo L, et al. Cryo-EM structure of influenza virus RNA polymerase complex at $4.3 \AA$ resolution. Mol Cell. 2015;57: 925-935. doi:10.1016/J.MOLCEL.2014.12.031

61. Biswas SK, Nayak DP. Mutational analysis of the conserved motifs of influenza A virus polymerase basic protein 1. J Virol. 1994;68: 1819-1826. doi:10.1128/JVI.68.3.18191826.1994

62. Ali S, Heathcote DA, Kroll SHB, Jogalekar AS, Scheiper B, Patel H, et al. The development of a selective cyclin-dependent kinase inhibitor that shows antitumor activity. Cancer Res. 2009;69: 6208-6215. doi:10.1158/0008-5472.CAN-09-0301

63. Nilsson BE, Velthuis AJW te, Fodor E. Role of the PB2 627 Domain in Influenza A Virus Polymerase Function. J Virol. 2017;91: 2467-2483. doi:10.1128/JVI.02467-16

64. Wille M, Holmes EC. The Ecology and Evolution of Influenza Viruses. Cold Spring Harb Perspect Med. 2020;10: 1-19. doi:10.1101/CSHPERSPECT.A038489

65. Doamekpor SK, Sanchez AM, Schwer B, Shuman S, Lima CD. How an mRNA capping enzyme reads distinct RNA polymerase II and Spt5 CTD phosphorylation codes. Genes Dev. 2014;28: 1323-36. doi:10.1101/gad.242768.114

66. Bortz E, Westera L, Maamary J, Steel J, Albrecht RA, Manicassamy B, et al. Host- and strainspecific regulation of influenza virus polymerase activity by interacting cellular proteins. MBio. 2011;2: 1-10. doi:10.1128/mBio.00151-11

67. Martinez-Rucobo FW, Kohler R, van de Waterbeemd M, Heck AJR, Hemann M, Herzog F, et al. Molecular Basis of Transcription-Coupled Pre-mRNA Capping. Mol Cell. 2015;58: 107989. doi:10.1016/j.molcel.2015.04.004

68. Fianu I, Chen Y, Dienemann C, Dybkov O, Linden A, Urlaub H, et al. Structural basis of Integrator-mediated transcription regulation. Science. 2021;374: 883-887. doi:10.1126/SCIENCE.ABK0154

69. Bradel-Tretheway BG, Mattiacio JL, Krasnoselsky A, Stevenson C, Purdy D, Dewhurst S, et al. Comprehensive proteomic analysis of influenza virus polymerase complex reveals a novel association with mitochondrial proteins and RNA polymerase accessory factors. J Virol. 2011;85: 8569-81. doi:10.1128/JVI.00496-11

70. Pflug A, Gaudon S, Resa-Infante P, Lethier M, Reich S, Schulze WM, et al. Capped RNA primer binding to influenza polymerase and implications for the mechanism of cap-binding inhibitors. Nucleic Acids Res. 2018;46: 956-971. doi:10.1093/NAR/GKX1210 


\section{Figure Legends}

Figure 1. Structural analysis of CTD binding to influenza B polymerase.

A. Overall view of the crystal structure of influenza B polymerase, with bound vRNA 5' hook (pink) and CTD peptide mimic (slate blue spheres) in site 2B. Ribbon diagram of the polymerase with PA (green), PB1 (cyan), PB2-N (red), PB2-cap-binding (orange), PB2midlink (magenta), PB2-627 (deep salmon).

B. Overall view of the crystal structure of influenza B polymerase with bound promoter (pink and yellow), capped primer (blue) and CTD peptide mimic (slate blue spheres) bound in sites $1 \mathrm{AB}$ and $2 \mathrm{~B}$. The polymerase is coloured as in (A). The $\mathrm{N}$ and C-termini of the two CTD fragments are marked and the red dotted line shows the shortest connection between them with directionality indicated by the arrow.

774 C. Overall view of the crystal structure of bat influenza A polymerase with bound promoter and CTD peptide mimic (slate blue spheres) bound in sites $1 \mathrm{AB}$ and $2 \mathrm{~A}$ ([32], PDB: 5M3H). The colour code is as in (A). The $\mathrm{N}$ and C-termini of the two CTD fragments are marked and the red dotted line shows the shortest connection between them with directionality indicated by the arrow.

D. Details of the interaction between key residues of the influenza B polymerase PA subunit site $2 \mathrm{~B}$. Three CTD repeats denoted a (orange), b (cyan) and c (dark green) are involved in this interaction. Hydrogen bonds are indicated as dotted green lines.

783 E. Sequence alignment of the CTD binding sites in the A/WSN/33 (A0A2Z5U3X0) and 784 B/Memphis/13/2003 (Q5V8X3) polymerase subunits PA and PB2. Protein sequences were obtained from UniProt (https://www.uniprot.org/) and aligned with SnapGene ${ }^{\circledR}$ 6.0. Key residues for CTD binding are indicated in bold. Identical, similar and non-similar residues are highlighted in dark blue, light blue and orange, respectively. Residue submitted to mutagenesis in this study are indicated with their numbers above $\left(\right.$ FluPol $\left._{\mathrm{A}}\right)$ and below $\left(\mathrm{FluPol}_{\mathrm{B}}\right)$ the alignment, respectively.

Figure 2. Gaussia princeps luciferase-based FluPol - CTD binding assay.

A-B. G2-CTD was expressed by transient transfection in HEK-293T cells together with PB2, PB1 and PA of FluPol $(\mathrm{B} / \mathrm{Memphis} / 13 / 2003$, blue bars) or FluPol $\mathrm{A}$ (A/WSN/33, grey bars). Either PB2 (A, hatched bars) or PA (B, filled bars) were C-terminally tagged in frame with G1. As controls, the wild-type (wt) PB1 was replaced by the catalytic inactive PB1 D444A D445A mutant (i) or was omitted (-). Luciferase activities were measured in cell lysates at $24 \mathrm{hpt}$. 
Normalised luciferase ratios (NLRs) were calculated as described in the Materials and Methods section. The data shown are the mean $\pm \mathrm{SD}$ of at least three independent experiments performed in technical triplicates. ${ }^{* *} \mathrm{p} \leq 0.002 ; * * * p \leq 0.001$ (two-way ANOVA; Dunnett's multiple comparisons test).

801 C-D. The CTD binding of FluPol$_{\mathrm{A}}$ mutants PA K289A and R638A was investigated. HEK802293 T cells were transfected as described in (A) and (B), respectively. Relative Light Units 803 (RLUs) are expressed as percentages relative to the $\mathrm{FluPol}_{\mathrm{A}} \mathrm{PA}$ wt. The data shown are the 804 mean \pm SD of three independent experiments performed in technical triplicates. $* * p \leq 0.002$; $805 * * * \mathrm{p} \leq 0.001$ (one-way ANOVA; Dunnett's multiple comparisons test).

806 E. Schematic representation of the CTD constructs used in (F) and (G): the wild-type G2-CTD 807 (wt, top) and the G2-CTD in which all serine 5 residues were replaced with an alanine (S5A, 808 bottom).

809 F-G. The interaction of the wt or the S5A mutated CTD to FluPol $(\mathrm{F})$ or FluPol$_{\mathrm{A}}(\mathrm{G})$ was 810 investigated by transient transfection in HEK-293T cells as described in (A). The data shown 811 are the mean \pm SD of four independent experiments performed in technical triplicates. ${ }^{*} p \leq$ $8120.033 ; * * * p \leq 0.001$ (two-way ANOVA; Sidak's multiple comparisons test). In parallel, cell 813 lysates were analysed by western blot using antibodies specific for the pS5 or pS2 CTD, G.princeps luciferase (Gluc) and tubulin.

Figure 3. FluPol ${ }_{B}$ and FluPol$_{A}$ CTD-binding mode at site $1 \mathrm{AB}$.

817 A. Superposition of the similar CTD binding in sites 1AB on the PA subunit for influenza B 818 (B/Memphis/13/2003, green) and bat influenza A (A/little yellow-shouldered 819 bat/Guatemala/060/2010(H17N10), light grey) polymerases with the CTD peptide as a thin tube (respectively slate blue and light grey). Key conserved residues are indicated in their respective colours, as well as the $\mathrm{FluPol}_{\mathrm{B}}$-specific insertion (PA 608 loop) that is important for part of site 2B. See sequence alignment in Figure 1E.

823 B. HEK-293T cells were transfected with the indicated FluPol $(\mathrm{A} / \mathrm{WSN} / 33)$ and FluPol $\mathrm{B}_{\mathrm{B}}$

824 (B/Memphis/13/2003) site 1AB mutants, which were C-terminally tagged with the G1 fragment. 825 Cells were lysed at $24 \mathrm{hpt}$ and analysed by western blot using antibodies specific for G.princeps 826 luciferase (PA-G1) and tubulin. The residue numbering corresponds to FluPol$_{\mathrm{A}}(\mathrm{A} / \mathrm{WSN} / 33$ ).

827 C. In vivo CTD binding of the indicated mutants of FluPol ${ }_{\mathrm{A}}\left(\mathrm{A} / \mathrm{WSN} / 33\right.$, grey bars) and FluPol $\mathrm{B}_{\mathrm{B}}$ 828 (B/Memphis/13/2003, blue bars). The G2-tagged CTD was expressed by transient transfection in HEK-293T cells together with PB2, PB1 and PA-G1. RLUs are expressed as percentages relative to wt FluPol$/ \mathrm{A} / \mathrm{B}$. The data shown are mean $\pm \mathrm{SD}$ of three independent experiments 831 performed in technical triplicates. $* * * p \leq 0.001$ (two-way ANOVA; Dunnett's multiple 
comparisons test).

833 D. Characterisation of recombinant IAV (A/WSN/33, grey dots) and IBV (B/Brisbane/60/2008, 834 blue dots) viruses. Recombinant viruses with the indicated mutations were generated by reverse genetics as described in the Material and Methods section. Reverse genetic supernatants were titrated on MDCK cells, stained at 72 hpi and plaque diameters were determined using the Fiji software. Each dot represents the diameter of a viral plaque relative to the mean plaque size of IAV wt or IBV wt recombinant virus. (\#) not measurable pinhead-sized plaque diameter; (§) no viral rescue.

840 E. Polymerase activity of CTD-binding site $1 \mathrm{AB}$ mutants. FluPol $\mathrm{A}$ (A/WSN/33, grey bars) or FluPol $_{\mathrm{B}}$ (B/Memphis/13/2003, blue bars) was reconstituted in HEK-293T cells by transient transfection of PB2, PB1, PA, NP and a model RNA encoding the Firefly luciferase flanked by the 5' and 3' non-coding regions of the IAV or IBV NS segments, respectively. As an internal control, a RNA-Polymerase II promotor driven Renilla plasmid was used. Luminescence was measured at $24 \mathrm{hpt}$ as described in the Material and Methods section. Firefly activity was normalised to Renilla activity and is shown as percentages relative to wt FluPol$/ \mathrm{A}$. The data shown are the mean $\pm \mathrm{SD}$ of three independent experiments performed in technical duplicates. $* * * \mathrm{p} \leq 0.001$ (two-way ANOVA; Dunnett's multiple comparisons test).

Figure 4. FluPol ${ }_{B}$ and $\mathrm{FluPol}_{\mathrm{A}} \mathrm{CTD}$-binding mode at site $2 \mathrm{~A}$.

A. Superposition of CTD peptide (slate blue tube) bound at site $2 \mathrm{~A}$ of the PA subunit of FluPol$A$ (A/Zhejiang/DTID-ZJU01/2013(H7N9), green) with the equivalent region of FluPol ${ }_{B}$ (B/Memphis/13/2003, wheat), showing similarities and differences in CTD interacting residues. See sequence alignment Figure 1E.

856 B-E. Protein expression (B), in vivo CTD binding (C), characterisation of recombinant IAV and IBV viruses (D) and polymerase activity (E) of CTD-binding site 2A mutants. Experiments were performed as described in Figure 3 for $\mathrm{FluPol}_{\mathrm{B}}$ and $\mathrm{FluPol}_{\mathrm{A}}$ site $1 \mathrm{AB}$ mutations. C. ${ }^{* * *} \mathrm{p}$ pinhead-sized plaque diameter; ( ) no viral rescue, (n.d.) not determined. E. ***p $\leq 0.001$ (twoway ANOVA; Dunnett's multiple comparisons test).

864 A. Superposition of CTD peptide (slate blue tube) bound in site 2B of FluPol 865 (B/Memphis/13/2003, PA green, PB2-N red, PB2-627 deep salmon) with the equivalent region 866 of FluPol$_{\mathrm{A}}(\mathrm{A} / \mathrm{NT} / 60 / 1968$ (H3N2), [59], PDB: 6RR7, PA light green, PB2 pink), showing 
similarities and differences in CTD interacting residues. See sequence alignment Figure 1E.

B. Protein expression (left), in vivo CTD binding (middle), and polymerase activity of FluPolB PA R608A (right). Experiments were performed as described in Figure 3. The data shown are mean $\pm \mathrm{SD}$ of three independent experiments performed in technical triplicates. ${ }^{* * *} \mathrm{p} \leq 0.001$

871 (unpaired t test).

872 C-D. Protein expression (C) and in vivo CTD binding (D) of CTD-binding site 2B mutants. 873 Experiments were performed as described in Figure 3 for FluPol $_{\mathrm{B}}$ and $\mathrm{FluPol}_{\mathrm{A}}$ site $1 \mathrm{AB}$ 874 mutations. D. ${ }^{* *} \mathrm{p} \leq 0.002,{ }^{* * *} \mathrm{p} \leq 0.001$ (two-way ANOVA; Dunnett's multiple comparisons 875 test).

876 E. In vivo CTD binding of PB2 $\Delta 627$ domain deletion mutants was investigated. G2-CTD was expressed by transient transfection in HEK-293T cells together with PB2-G1, PB1 and PA of 878 FluPol $_{\mathrm{A}}\left(\mathrm{A} / \mathrm{WSN} / 33\right.$, grey bars) or $\mathrm{FluPol}_{\mathrm{B}}$ (B/Memphis/13/2003, blue bars). Luciferase activities were measured in cell lysates at 24 hpt. Normalised luciferase ratios (NLRs) were calculated as described in the Materials and Methods section. ***p $\leq 0.001$ (two-way ANOVA; Sidak's multiple comparisons test). Cell lysates were analysed in parallel by western blot with antibodies specific for the pS5 CTD, G. princeps luciferase (PB2-G1) and tubulin. CTD-binding site 2B mutants. Experiments were performed as described in Figure 3 for

FluPol ${ }_{\mathrm{B}}$ and $\mathrm{FluPol}_{\mathrm{A}}$ site $1 \mathrm{AB}$ mutations. F. (Æ) no viral rescue. G. ***p $\leq 0.001$ (two-way ANOVA; Dunnett's multiple comparisons test).

Figure 6. Effect of CTD pS5 peptides on in vitro endonuclease and transcription activity

890 A-B. CTD pS5 peptides of different lengths (two, four and six repeats) were added to (A) 891 FluPol $_{\mathrm{B}}(\mathrm{B} / \mathrm{Memphis} / 13 / 2003)$ or (B) FluPol$_{\mathrm{A}}$ (bat influenza A (A/little yellow-shouldered 892 bat/Guatemala/060/2010(H17N10)) in vitro activity reactions as described in Material and 893 Methods. The left four lanes show endonuclease and right four lanes transcription reactions. 894 Quantification of the reaction products of four independent experiments is shown below 895 (FluPol $\mathrm{B}$ in blue and FluPol in grey, respectively). The products of the reactions are normalised 896 to the total RNA amount for each reaction and are presented as fractions of the activity of the 897 reaction without peptide. ${ }^{*} \mathrm{p} \leq 0.033, * * * \mathrm{p} \leq 0.001$ (one-way ANOVA; Dunnett's multiple 898 comparisons test).

$900 \quad$ Figure 7. FluPol ${ }_{B}$ and FluPol ${ }_{A}$ binding to RPB1, RPB1 $\Delta C T D$ and RPB2.

901 A. Binding of $\mathrm{FluPol}_{\mathrm{A}}$ (A/WSN/33, grey bars) and FluPol $(\mathrm{B} / \mathrm{Memphis} / 13 / 2003$, blue bars) to 
902 RPB1, RPB1 $\triangle$ CTD and RPB2 was evaluated. RPB1, RPB1 $\triangle$ CTD and RPB2 were tagged to

903 G2 and expressed by transient transfection in HEK-293T cells together with PB2, PB1 and PA-

904 G1. Normalised luciferase activities (NLRs) were calculated as described in the Materials and

905 Methods section. The data shown are the mean \pm SD of five independent experiments

906 performed in technical triplicates. ${ }^{*} \mathrm{p} \leq 0.033,{ }^{*} \mathrm{p} \leq 0.002$ (two-way ANOVA; Dunnett's

907 multiple comparisons test). Cell lysates were analysed in parallel by western blot with

908 antibodies specific for the pS5 CTD, G. princeps luciferase and tubulin.

909 B-C. Binding of (B) FluPol $(\mathrm{B} / \mathrm{Memphis}$ 13/2003) and (C) FluPol $\mathrm{A}(\mathrm{A} / \mathrm{WSN} / 33)$ mutants in 910 site 2B (PB2 K556/R555A), site 1 (PA K631A R634A/ PA K635A R638A) and site 2A (PA

$911 \mathrm{~K} 450 \mathrm{~A} / \mathrm{PA}$ R454A) to RPB1, RPB1 $\triangle \mathrm{CTD}$ and RPB2 was evaluated as described in (A).

913 Figure S1. Omit maps for bound CTD peptide structures.

914 A. CTD peptide bound in site 2B of FluPol ${ }_{\mathrm{B}}$ (B/Memphis/13/2003) polymerase. Fo-Fc omit 915 map shown at $2.5 \sigma$ with clear density for two phosphoserines (pS5a and pS5b).

916 B. CTD peptide bound in site $2 \mathrm{~A}$ of FluPol $_{\mathrm{A}}$ (A/Zhejiang/DTID-ZJU01/2013(H7N9))

917 polymerase. Fo-Fc omit map shown at $2.7 \sigma$ with clear density for one phosphoserine.

919 Figure S2. Structural analysis of CTD binding in FluPol $_{A}$ and FluPol ${ }_{B}$.

920 A. Superposition of the PB2-627 domains of CTD-bound (deep salmon with CTD in slate-blue) 921 and unbound (wheat) FluPol (B/Memphis/13/2003) polymerase, showing induced-fit 922 conformational changes of three key hydrophobic residues (PB2 W553, M572, W575).

923 B. Details of the binding of the CTD peptide (slate blue) in site $2 \mathrm{~A}$ of FluPol$_{\mathrm{A}}$ 924 (A/Zhejiang/DTID-ZJU01/2013(H7N9) core) polymerase.

925 C. Comparison of site 1A configuration for CTD bound form of $\mathrm{FluPol}_{\mathrm{A}}$ (bat influenza A 926 (A/little yellow-shouldered bat/Guatemala/060/2010(H17N10) [32], PDB: 5M3H, PA subunit 927 light grey, CTD peptide slate-blue), CTD free, transcription active form of FluPol 928 (A/NT/60/1968 (H3N2), [59], PDB: 6RR7, wheat) and dimeric FluPol ${ }_{\mathrm{A}}$ (A/Zhejiang/DTID929 ZJU01/2013(H7N9) core, light blue, this work). The FluPol (H7N9) polymerase core is the 930 symmetrical dimer with each polymerase in the open, 'dislocated' state [18]. Due to the 931 dislocation, PA regions $425-452$ and 586-618 are rotated by $\sim 20^{\circ}$, which particularly effects 932 the position of site 1A binding site residues Y445, E449 and F612. This likely explains the lack 933 of CTD binding observed in site 1A for the H7N9 core, whereas site 2A is undistorted and 934 occupied by CTD (Fig. S2B). 
(A0A2Z5U3X0) and B/Memphis/13/2003 (Q5V8X3).

938 Protein sequences were obtained from UniProt (https://www.uniprot.org/), aligned with SnapGene ${ }^{\circledR} 6.0$ and visualized by Espript 3.0 [55].

Figure S4. FluPol-CTD interaction in the presence of a CDK7 inhibitor.

942 A. HEK-293T cells were transfected with G2-CTD. At 24 hpt cells were treated for $1 \mathrm{~h}$ with 20 $\mu \mathrm{M}$ BS-181-HCl (DMSO final concentration $0.2 \%$ ). Cell lysates were analysed by western

944 blot with antibodies specific for pS5 or pS2 CTD and tubulin.

945 B. In vivo CTD binding of FluPol $(\mathrm{A} / \mathrm{WSN} / 33)$ and $\mathrm{FluPol}_{\mathrm{B}}\left(\mathrm{B} / \mathrm{Memphis}_{\mathrm{A}}\right.$ 13/2003). G2-tagged 946 CTD was expressed by transient transfection in HEK-293T cells together with the viral 947 polymerase subunit PB2, PB1 and PA-G1. At $24 \mathrm{hpt}$ cells were treated for $1 \mathrm{~h}$ with $20 \mu \mathrm{M}$ BS$948 \quad 181-\mathrm{HCl}$ or $0.2 \% \mathrm{DMSO}$ before cell lysis and measurement of G. princeps luciferase activity 949 as described in the Material and Methods section. As a control, the previously described FluPol $\mathrm{A}$ 950 - NUP62 interaction was investigated by co-transfection of G2-NUP62, PB2, PB1 and PA-G1. 951 RLUs are expressed as percentages relative to DMSO treated cells. The data shown are mean $952 \pm$ SD of five independent experiments performed in technical triplicates. ${ }^{* * *} \mathrm{p} \leq 0.002,{ }^{*} * \mathrm{p} \leq$ 0.001 (two-way ANOVA; Dunnett's multiple comparisons test).

Figure S5: In vivo CTD binding of FluPol $_{\mathrm{A}}$ and FluPol $\mathrm{B}_{\mathrm{B}}$ mutants.

956 A-C. In vivo $\mathrm{CTD}$ binding of the indicated site $1 \mathrm{AB}(\mathrm{A})$, site $2 \mathrm{~A}(\mathrm{~B})$ and site $2 \mathrm{~B}(\mathrm{C})$ mutants of FluPol${ }_{\mathrm{A}}\left(\mathrm{A} / \mathrm{WSN} / 33\right.$, grey hatched bars) and FluPol${ }_{\mathrm{B}}(\mathrm{B} / \mathrm{Memphis} / 13 / 2003$, blue hatched bars). The G2-tagged CTD was expressed by transient transfection in HEK-293T cells together with PB2-G1, PB1 and PA. RLUs are expressed as percentages relative to wt FluPol $\mathrm{A}_{\mathrm{B}}$. The data shown are the mean \pm SD of at least three independent experiments performed in technical triplicates. ${ }^{* * *} \mathrm{p} \leq 0.002,{ }^{* * *} \mathrm{p} \leq 0.001$ (two-way ANOVA; Dunnett's multiple comparisons test). (n.d.) not determined.

\section{Figure S6: Plaque phenotype of FluPolB PA R608A}

965 Characterisation of recombinant IBV (B/Brisbane/60/2008) PA R608A mutant virus. Recombinant viruses with the indicated mutations were generated by reverse genetics as described in the Material and Methods section. Reverse genetic supernatants were titrated on MDCK cells and stained at $72 \mathrm{hpi}$ by crystal violet. The pictures show one representative plaque assay with the indicated ten-fold dilution. 
972 The RPB1 CTD sequences of Sus scrofa (wild boar), Equus caballus (horse), Homo sapiens

973 (human), Canis lupus (wolf), Mus musculus (house mouse), Gallus gallus (chicken) and Anas

974 platyrhynchos (wild duck) were obtained as described in the Material and Methods section,

975 aligned with SnapGene ${ }^{\circledR} 6.0$ and visualised by Espript 3.0 [55]. The CTD repeat numbers are

976 indicated below the sequence alignment. Identical and similar residues are indicated in red or

977 yellow, respectively.

978 


\section{Figure 1}

A

FluPol $_{B}(\mathbf{P 2})_{1}$

PA-endonuclease

B

FluPol $_{\mathrm{B}}\left(\mathrm{P}_{2} 21\right)$

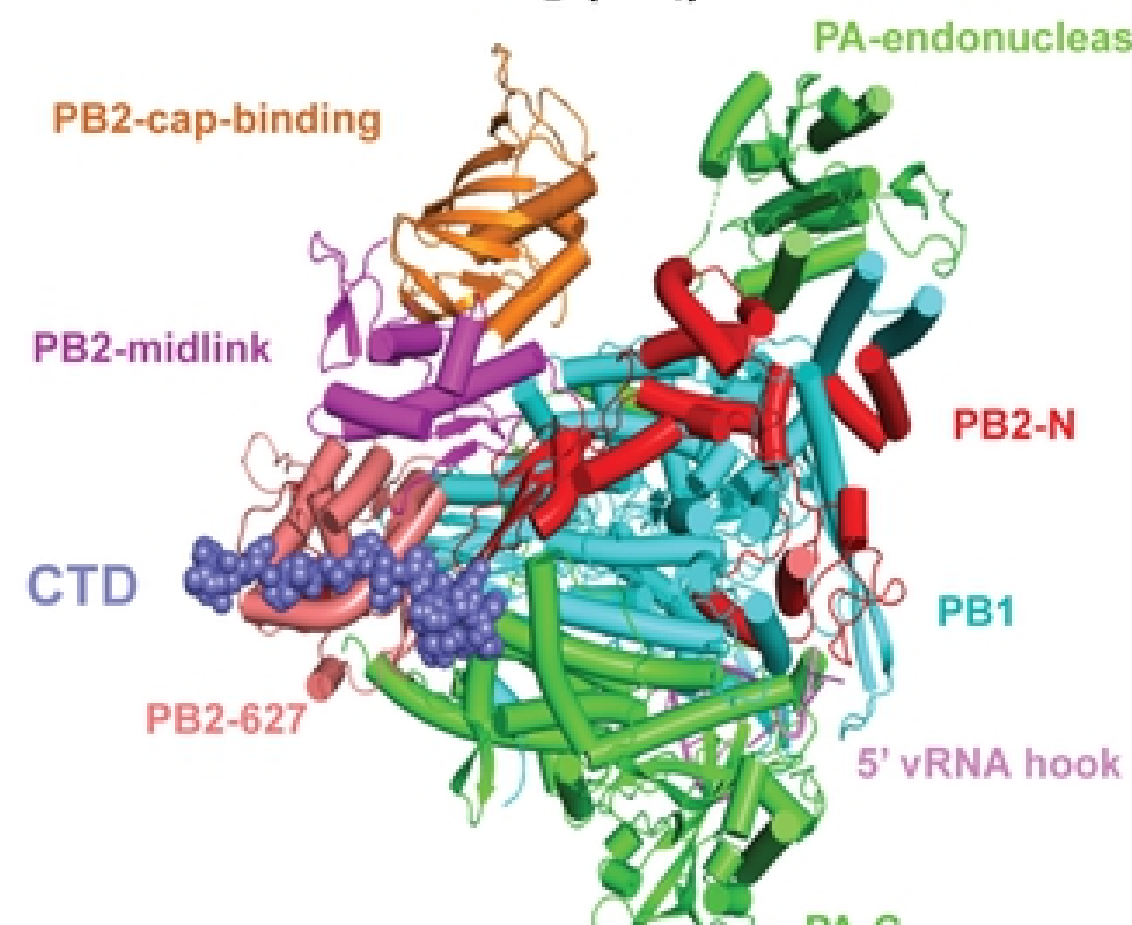
perper

C Bat FluPol (Lukarska et al.)

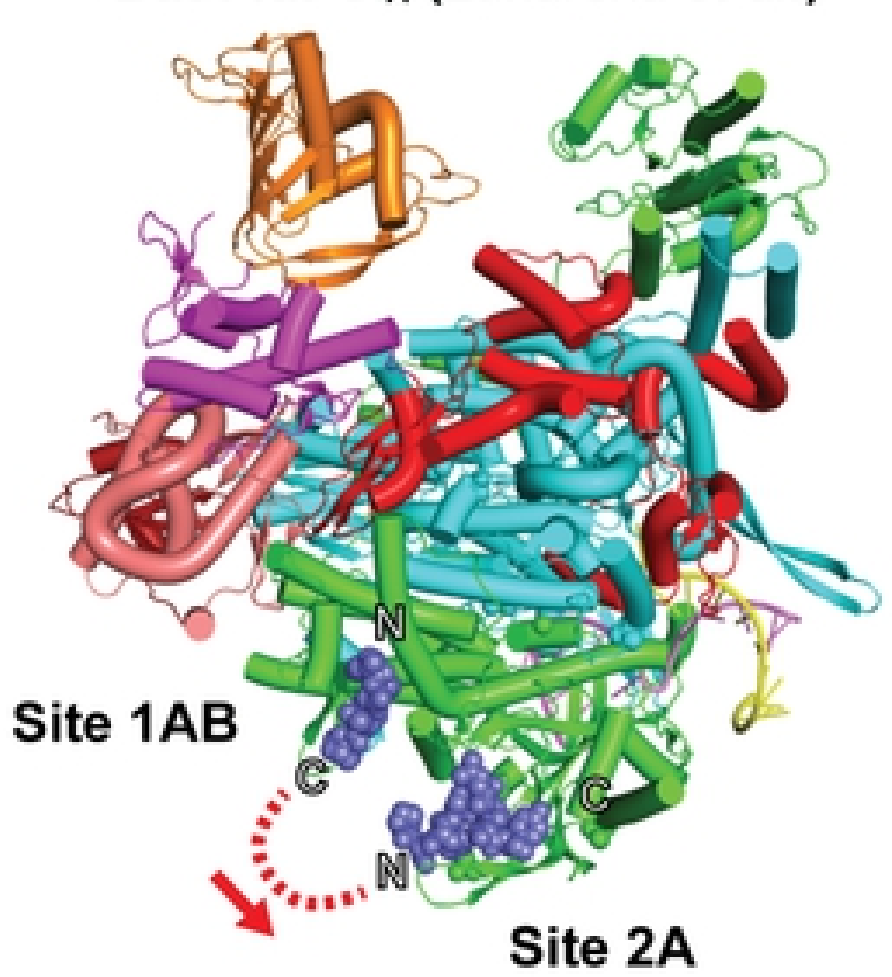

Site 2B

Site 1AB

Site 2B FluPol $\left(\mathbf{P 2}_{1}\right)$
D

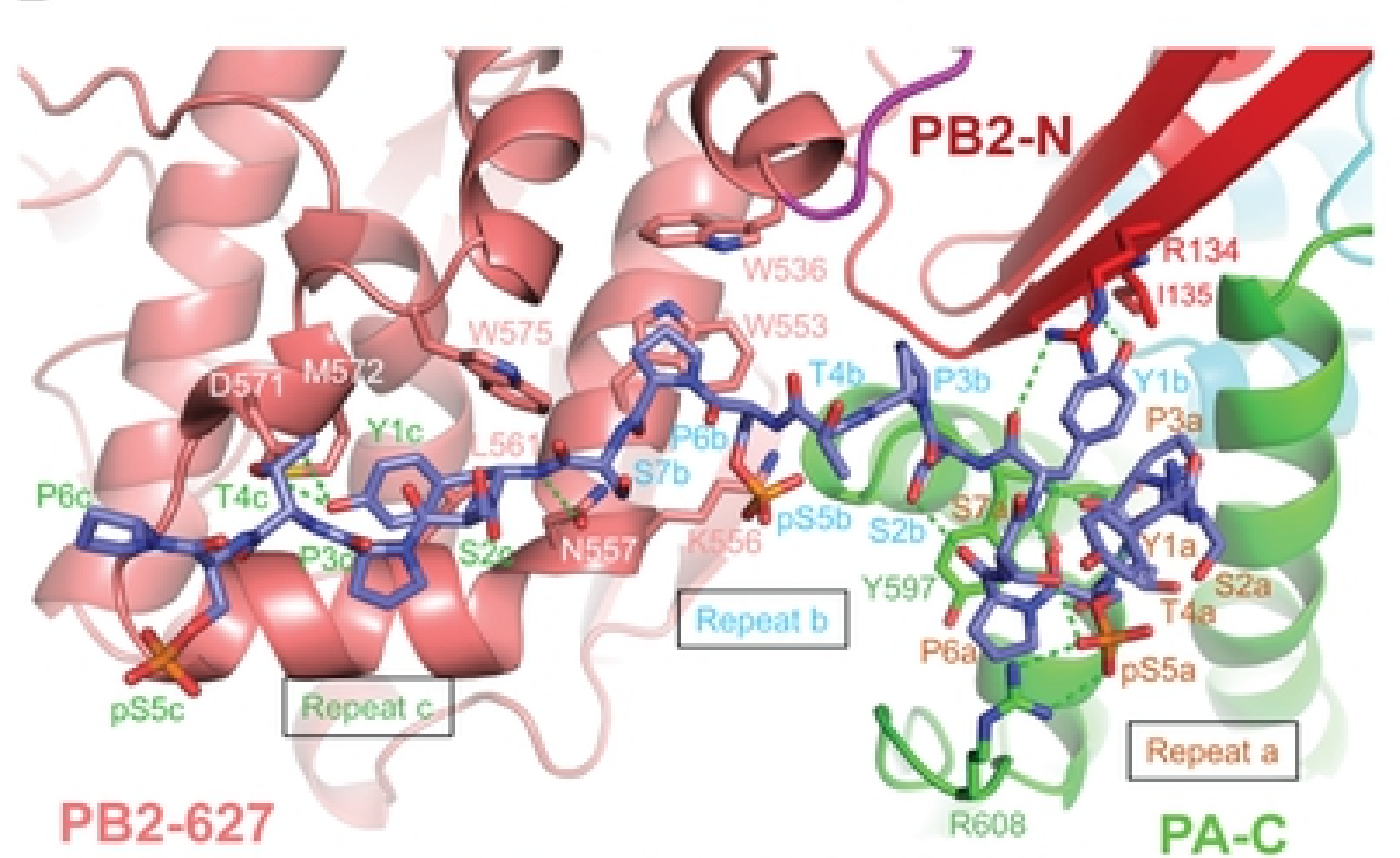

... YSPTpSPS YSPTpSPS YSPTpSP ...

Repeat a Repeat b Repeat c

\section{E PA Site 1AB}

A/WSN/1933

B/Memphis/13/2003

439-RKYFVNEIN-447

443-RNYETAEVS-451

PA Site 2A

A/WSN/1933

B/Memphis/13/2003

284-LMDA- LKLS-291

284-LMSDELGLA-292

PB2 Site 2B

A/WSN/1933

B/Memphis/13/2003
125-LKHGT FGPVH-134 127-LDNATWGRIT-136
631 -GSEGKALR VI -640

627-GSIGKVCRTL- 636
415-CELTDSSWIE-424 411-STLTSKRALD-420
450-VSHCRATEYI - 459 446-INYCKASTVM-455

450

550-YCWI 555 RNWET VKIOWSONPT MIYNKMEFEP-579 551 - YCWVLKNLVT LKAQFLLGKE DMFCWDAFEA-580
$544-E V G L M L$ IRSA IGHVSRPMFL- 563 540-RIGSLFVSGR ----EKSVYL-555

\section{PA Site 2B}

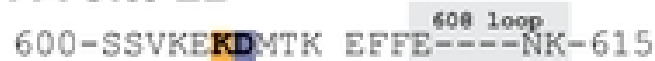
592-SSIQGYDNTK ACFKGDRVNS-611 
Figure 2

A
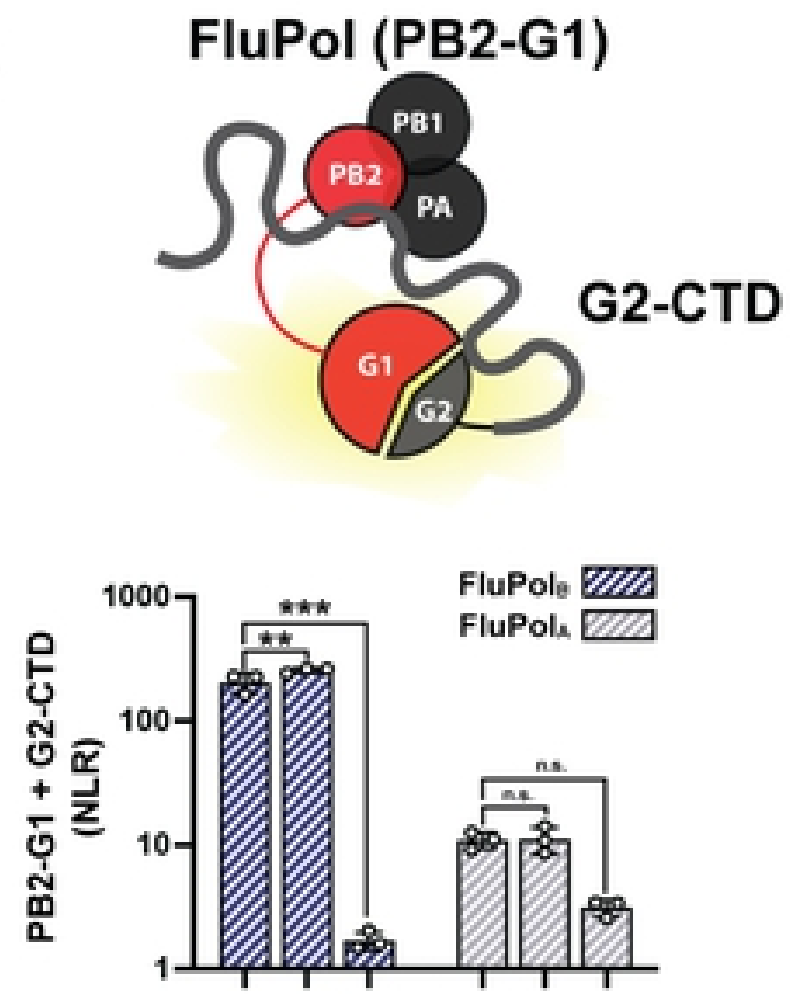

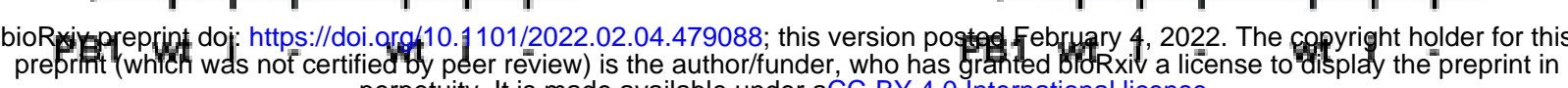

E

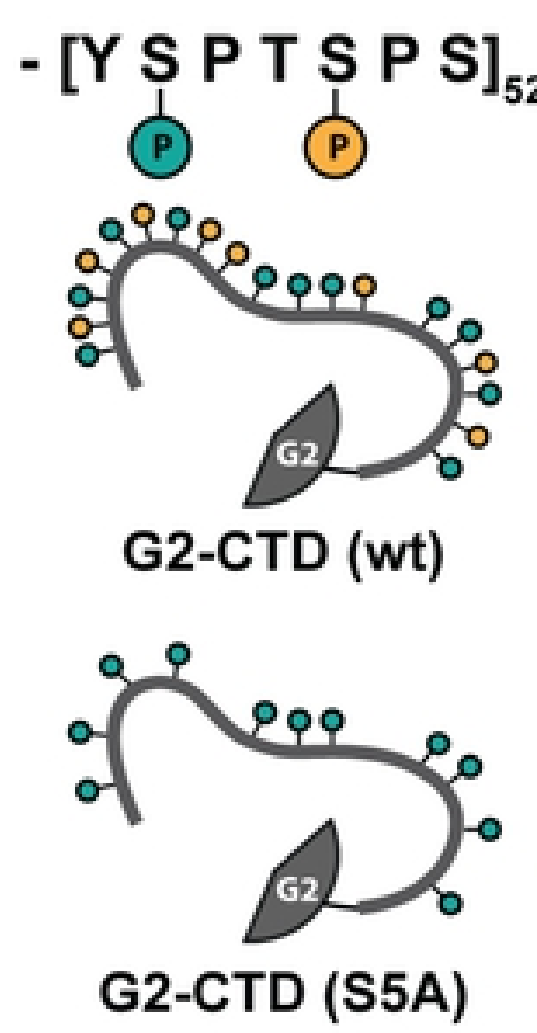

B
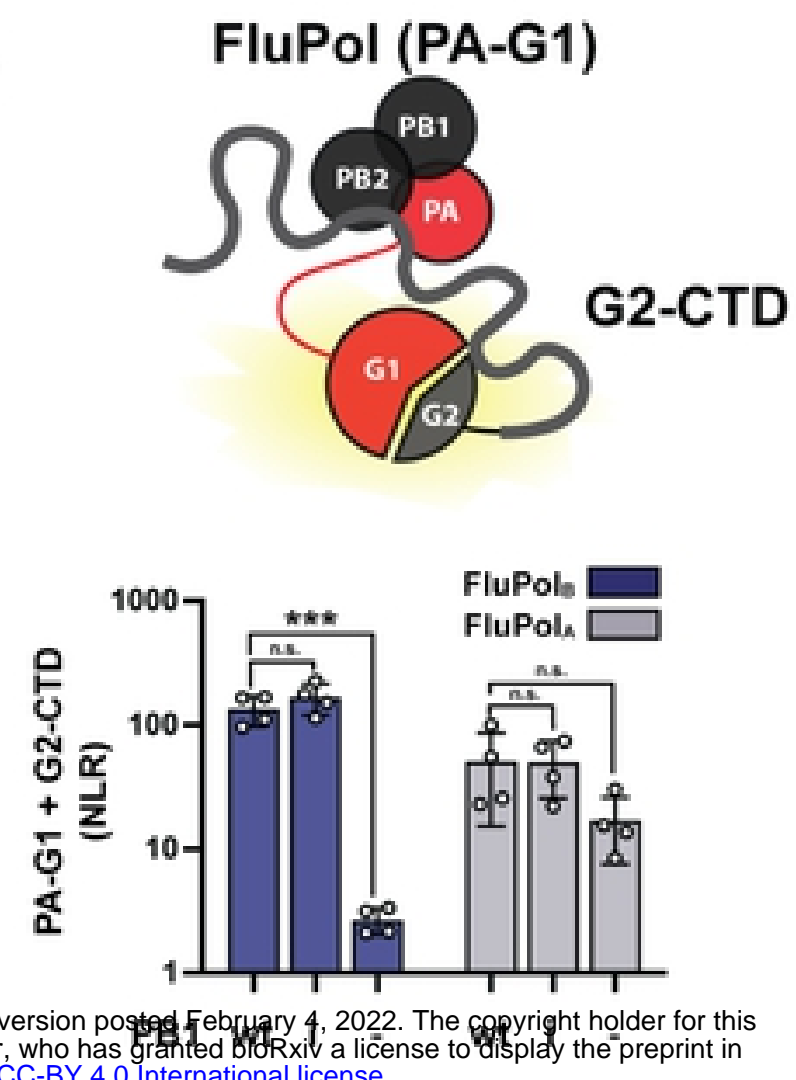

FluPols $\square$
F

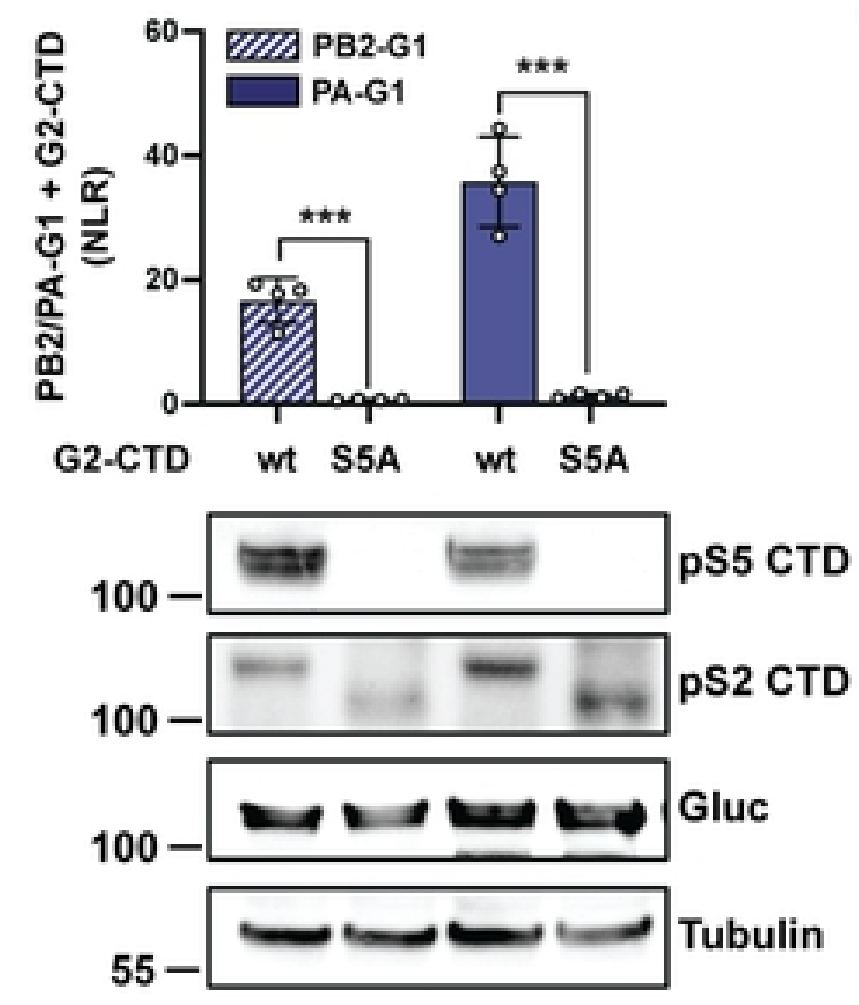

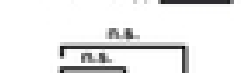

C

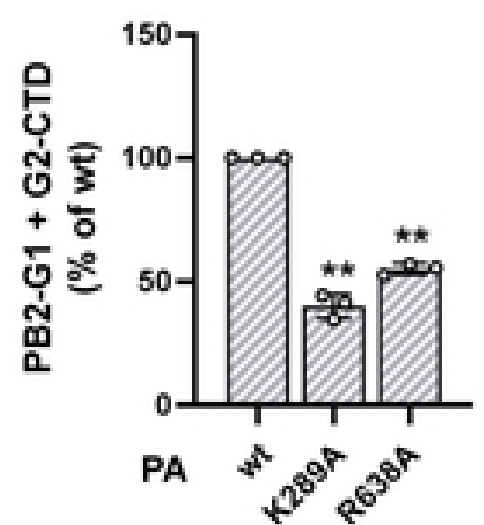

D

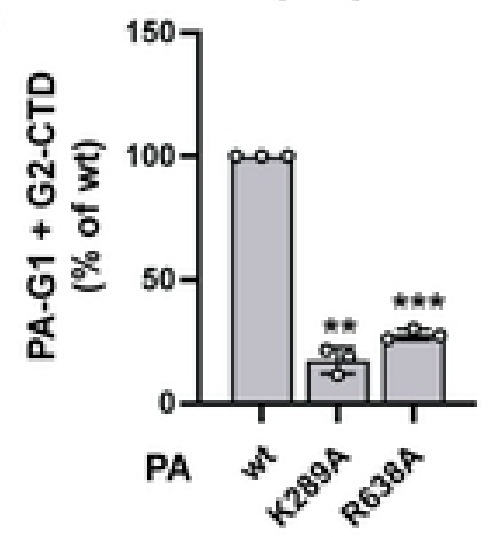

G

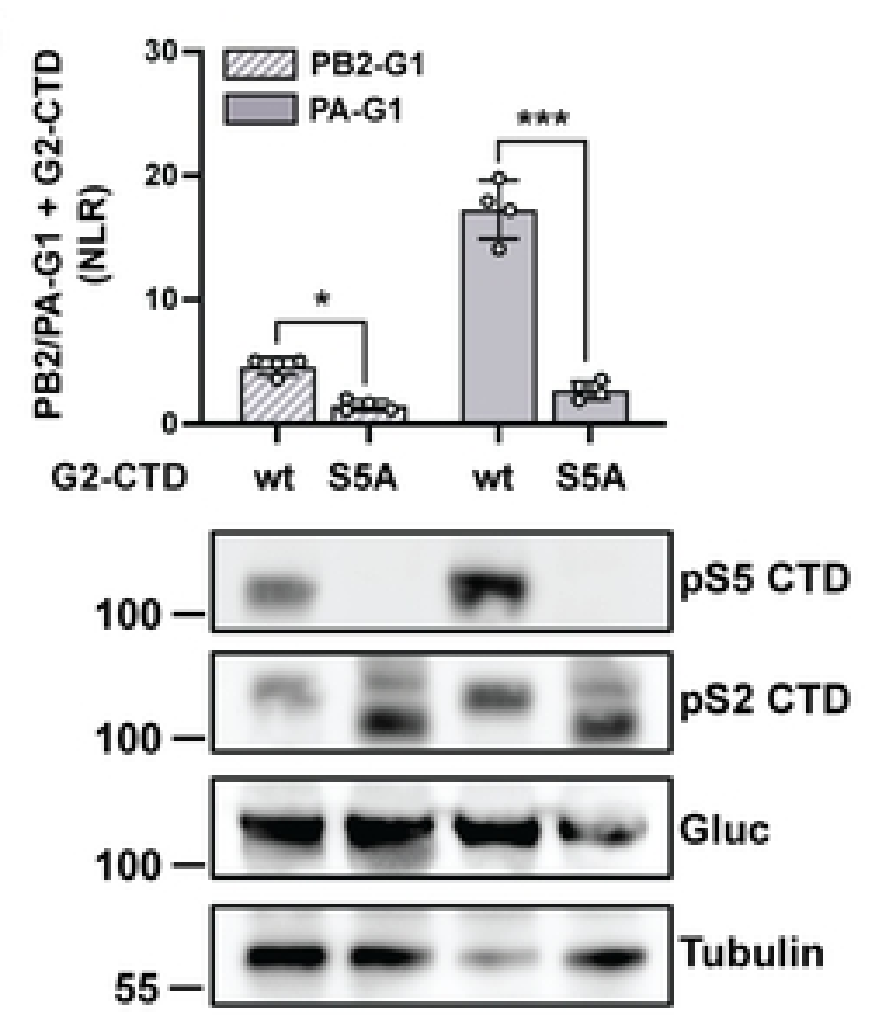


Figure 3
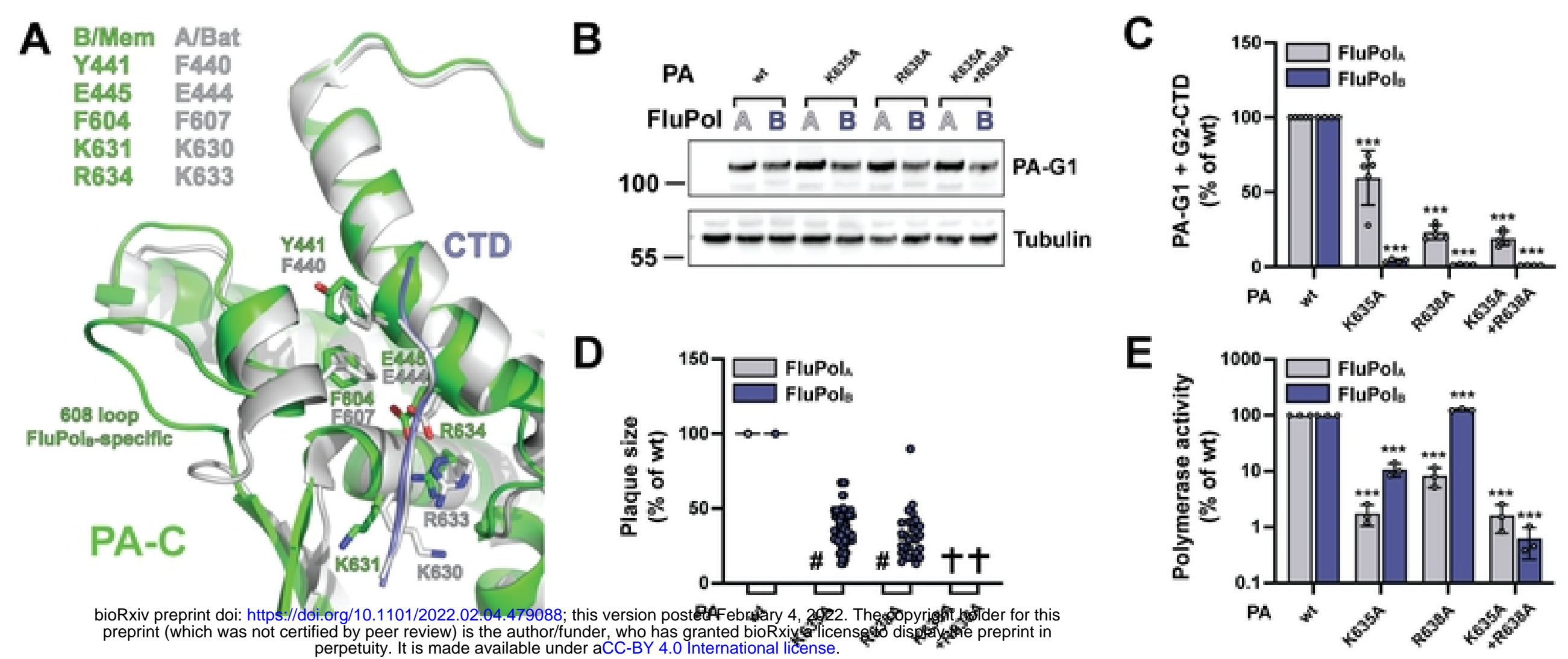
Figure 4
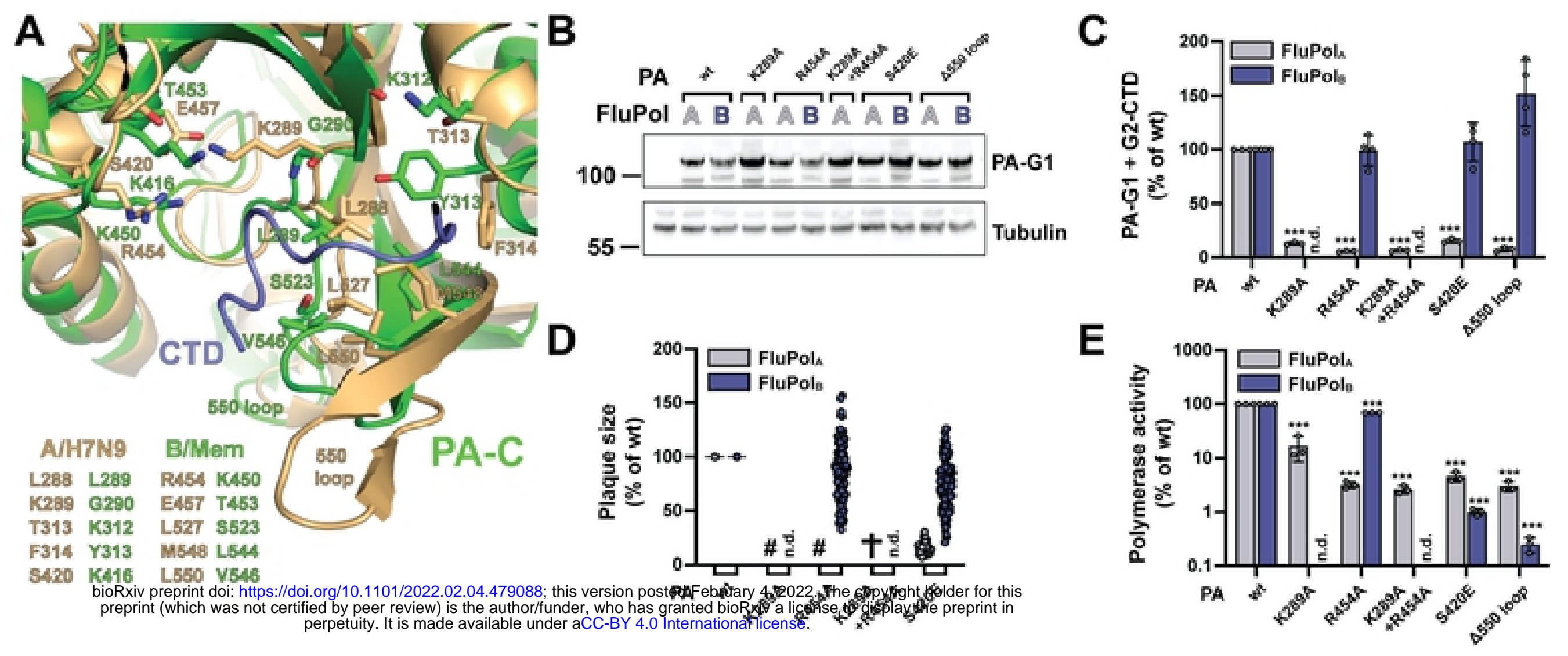
Figure 5

A

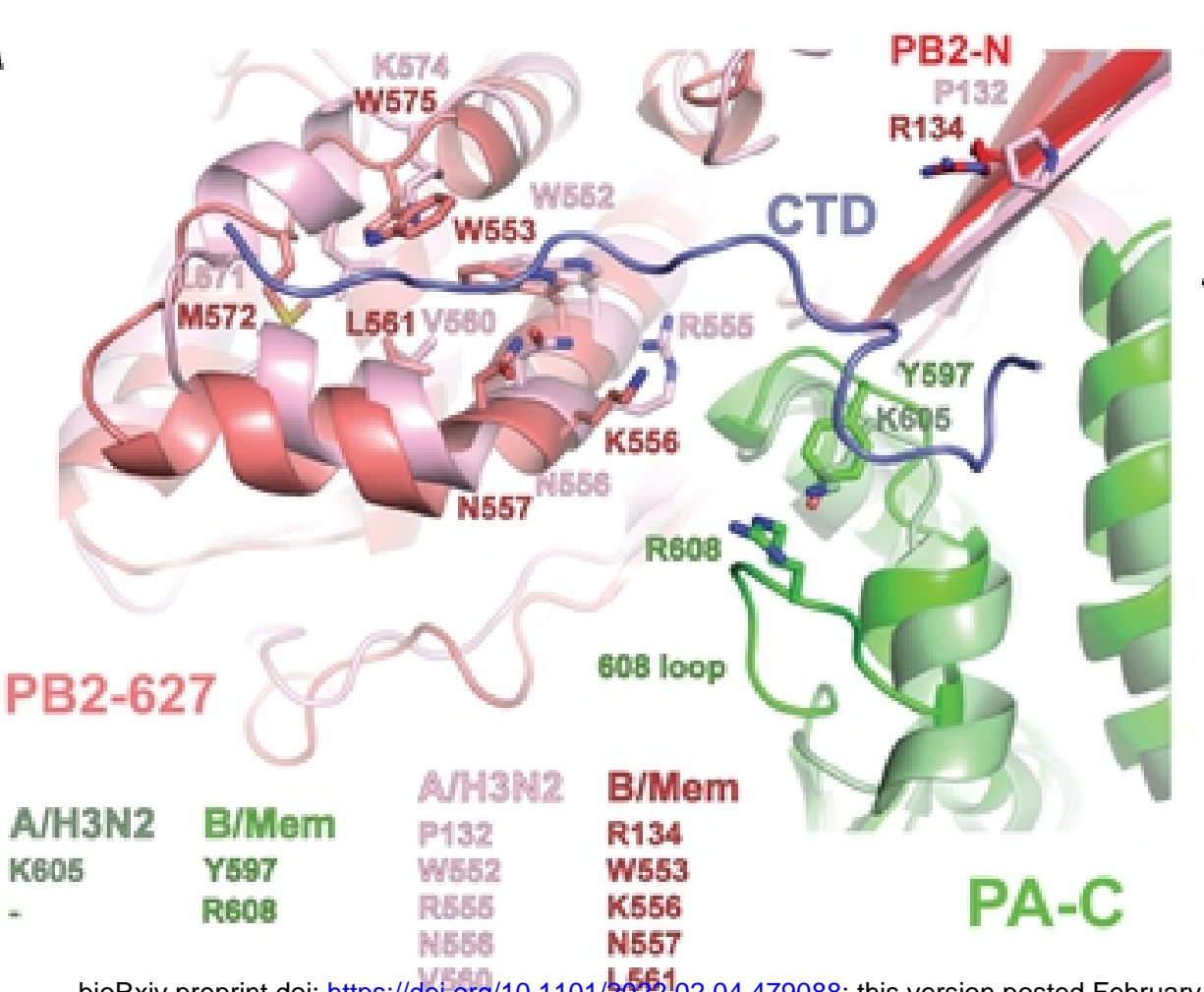

C

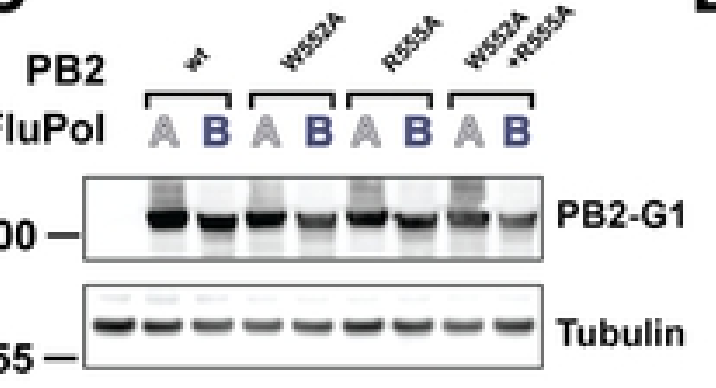

E

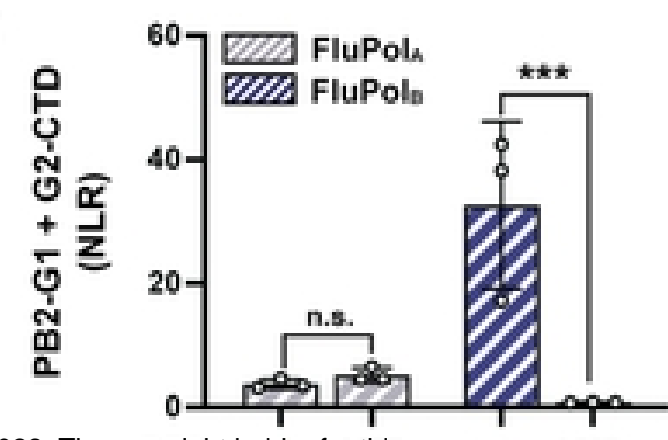

bioRxiv preprint doi: https://doi.org/10.1101/20222.02.04.479088; this version posted February 4, 2022. The coppgight halder fostthis

B
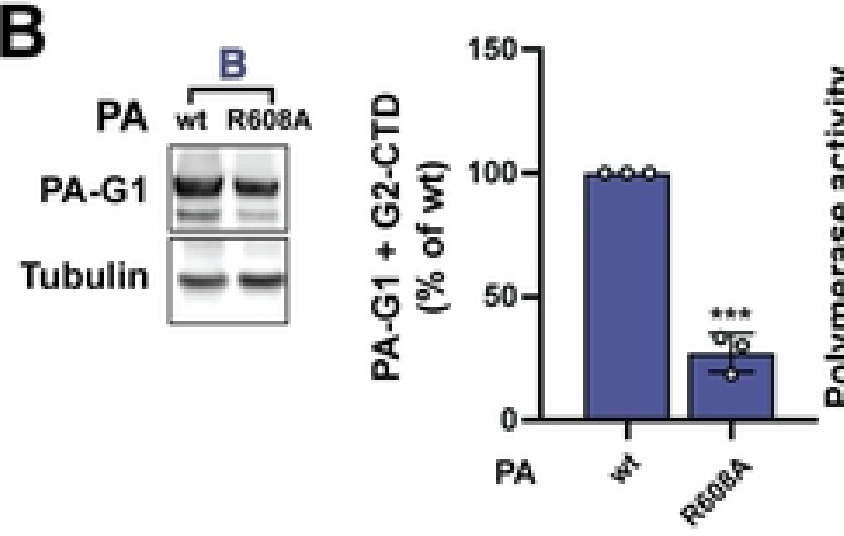

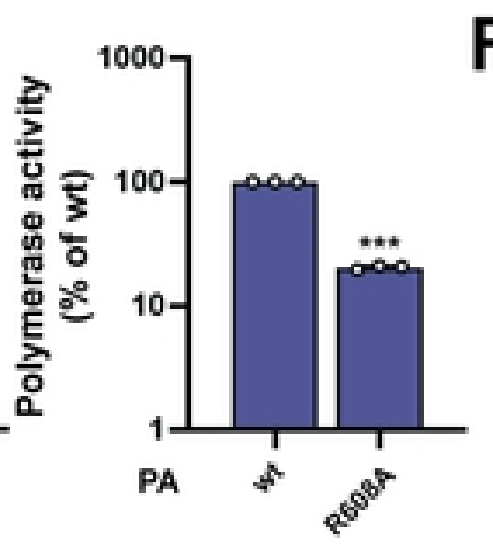

F

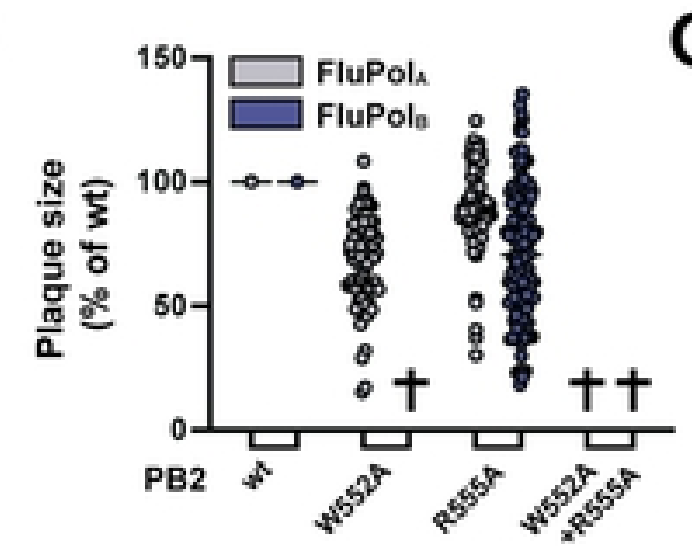

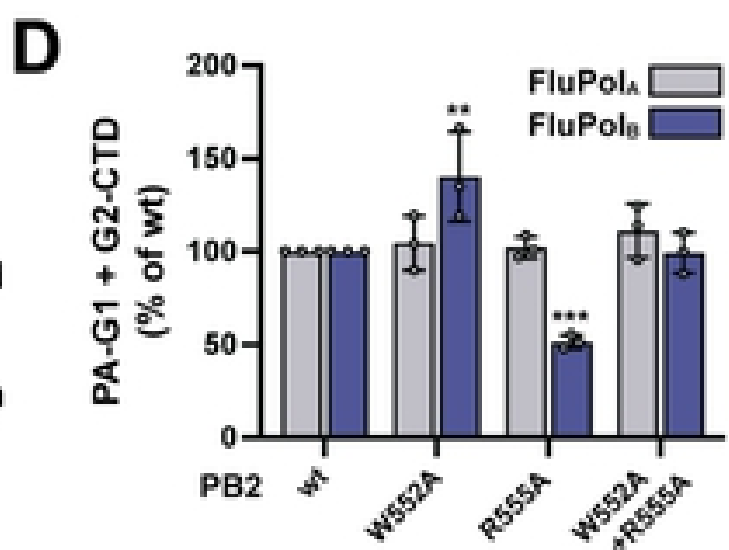

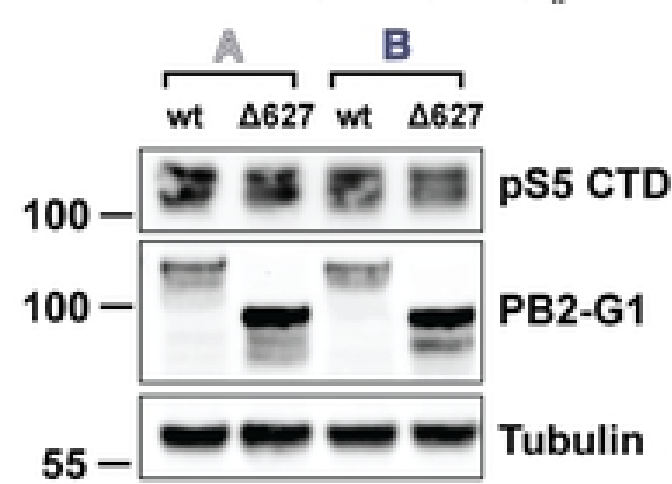

G

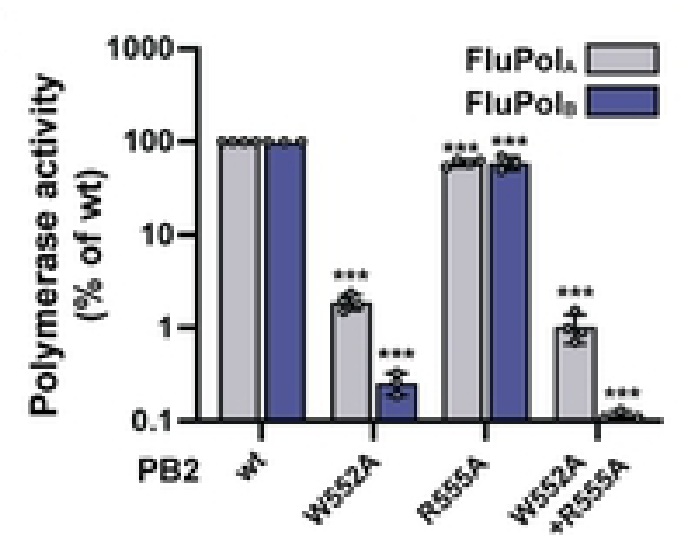


Figure 6

A
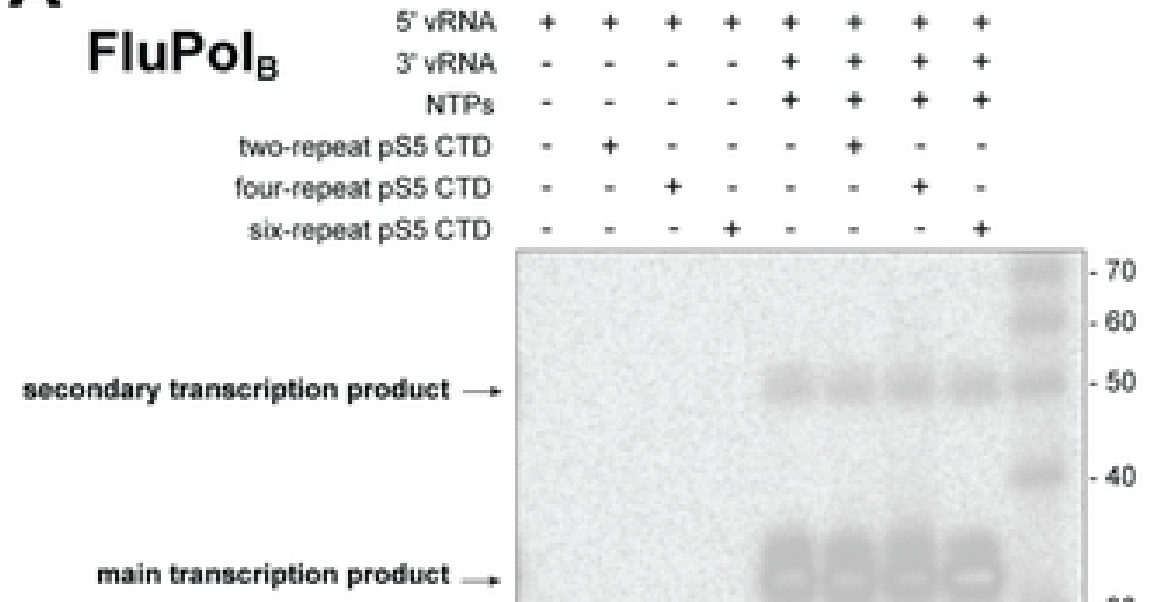

main transeription product $\rightarrow$

capped RNA $\rightarrow$

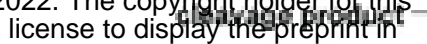
perpetuity. It is made available under aCC-BY 4.0 International license.
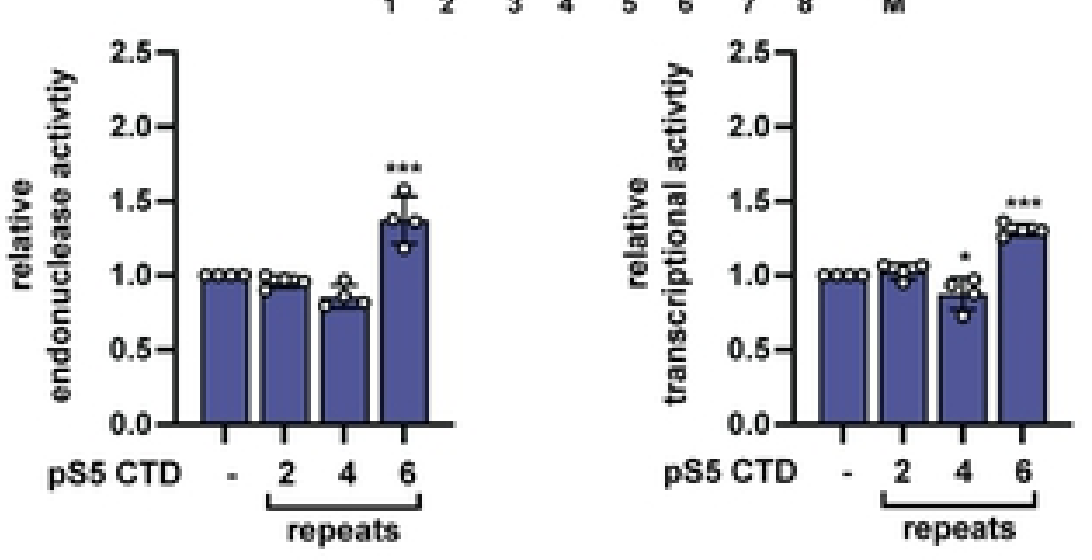

B
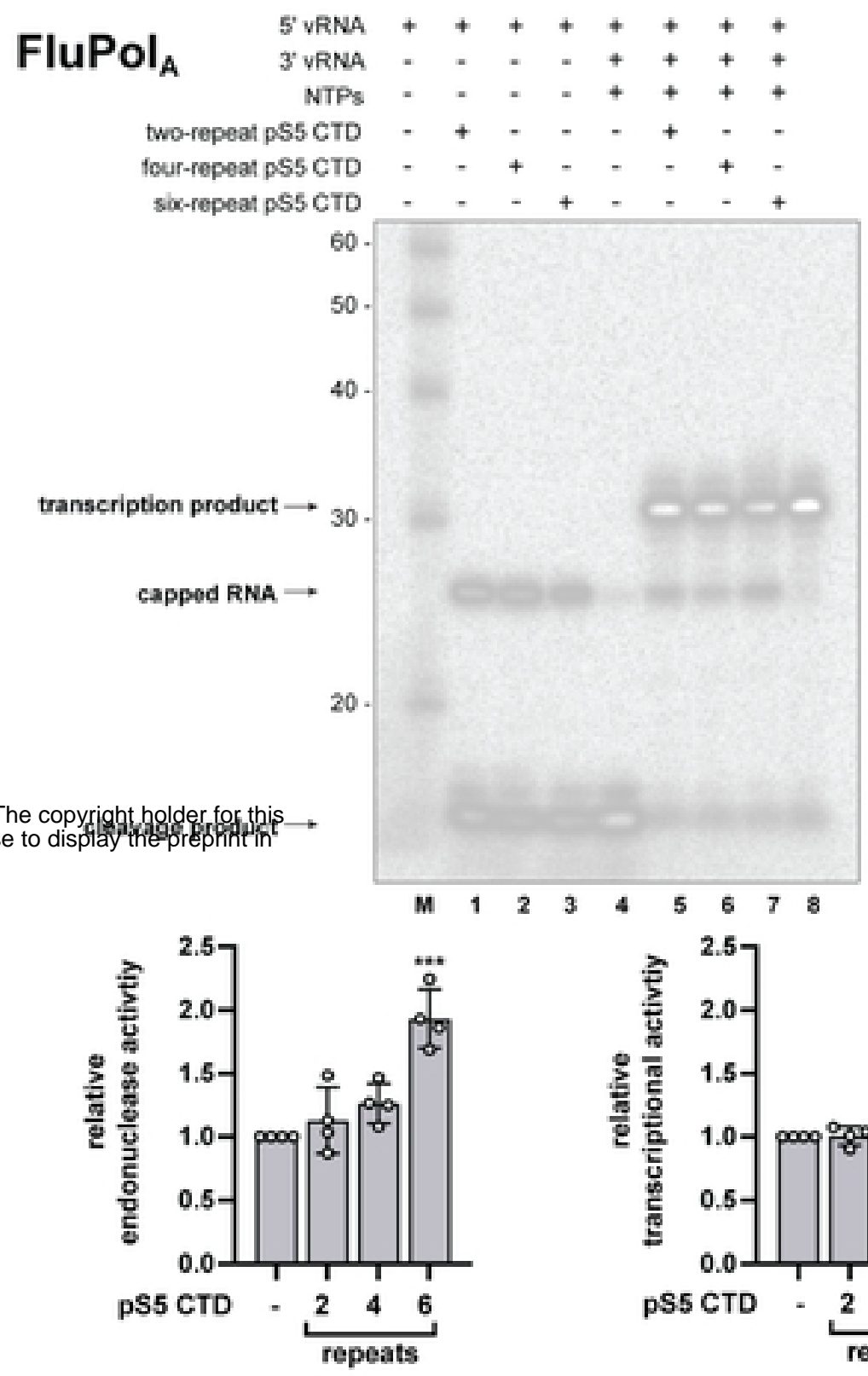
Figure 7

A
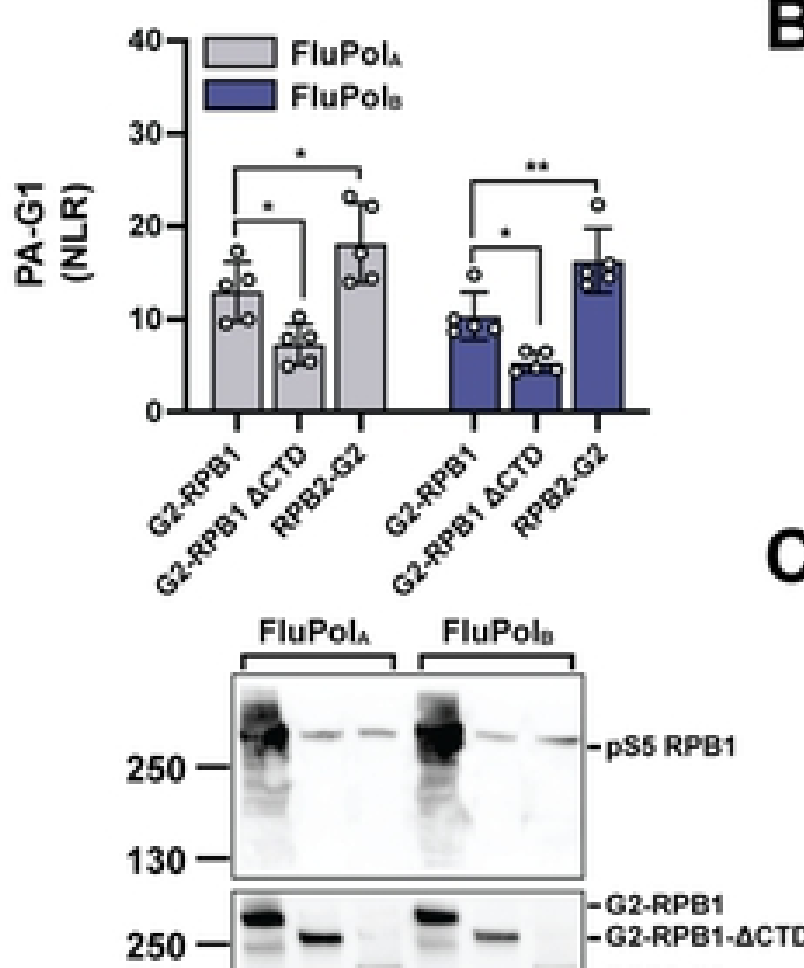

B

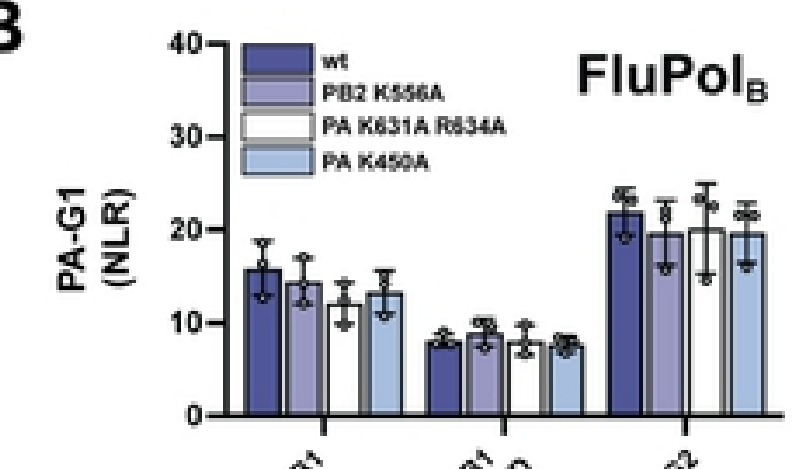

C

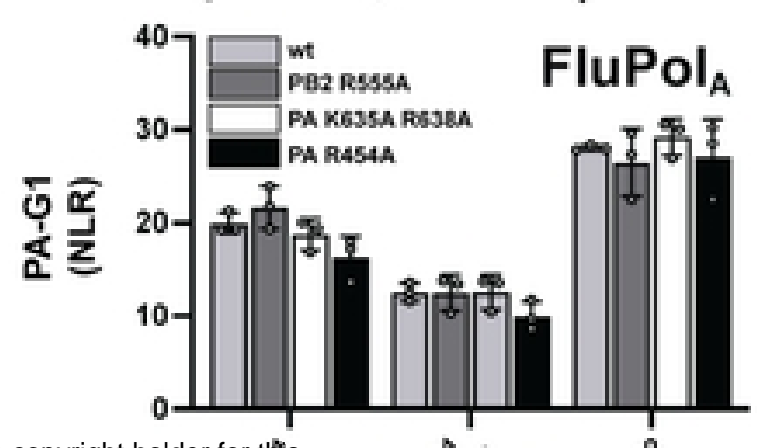

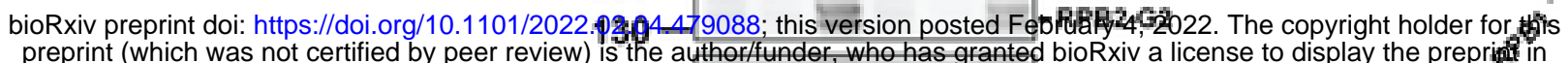

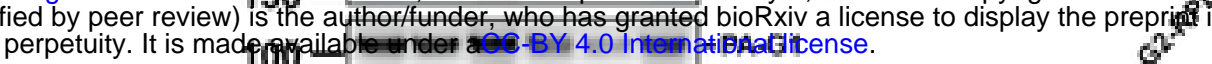

$$
55-
$$

$88^{8}$ 


\section{Figure S1}

A

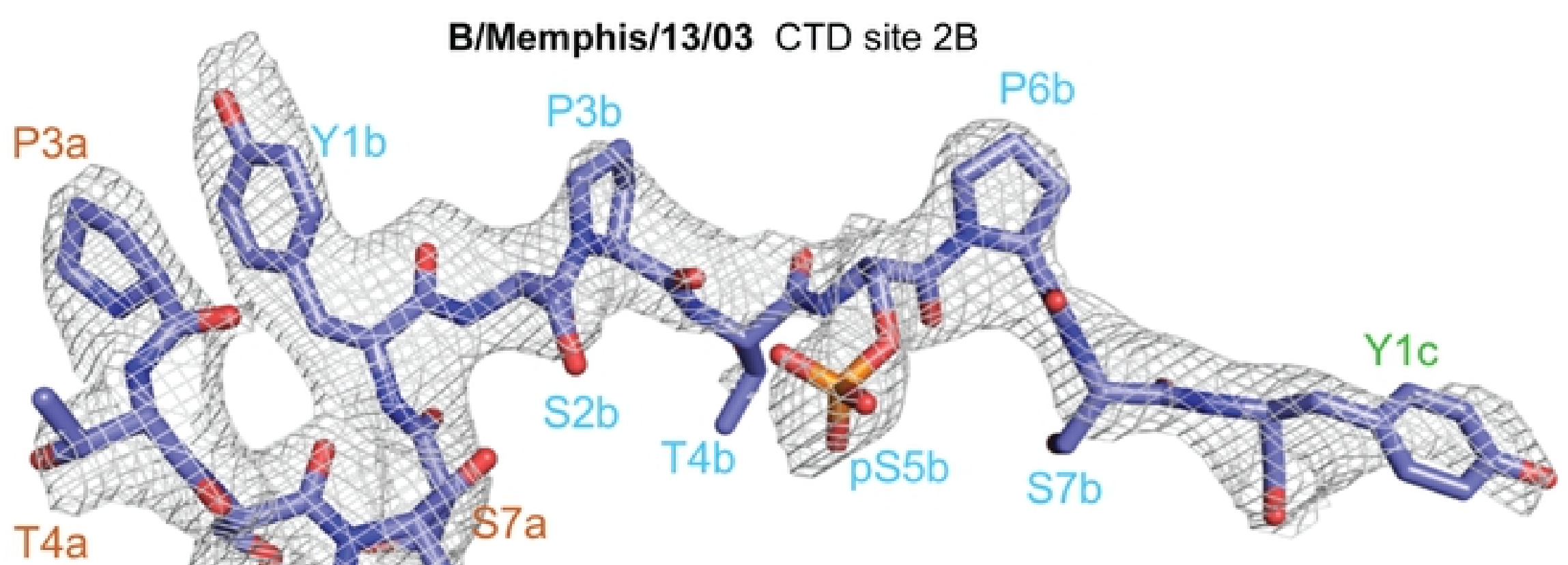

pS5a

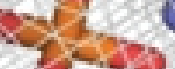

8

Fo-Fc omit map for CTD peptide contoured at $2.5 \sigma$

bioRxiv preprint doi: https://doi.org/10.1101/2022.02.04.479088; this version posted February 4, 2022. The copyright holder for this preprint (which was not certified by peer review) is the author/funder, who has granted bioRxiv a license to display the preprint in

B A/Zhejiang/DTID-ZJU01/2013(H7N9) CTD site 2A

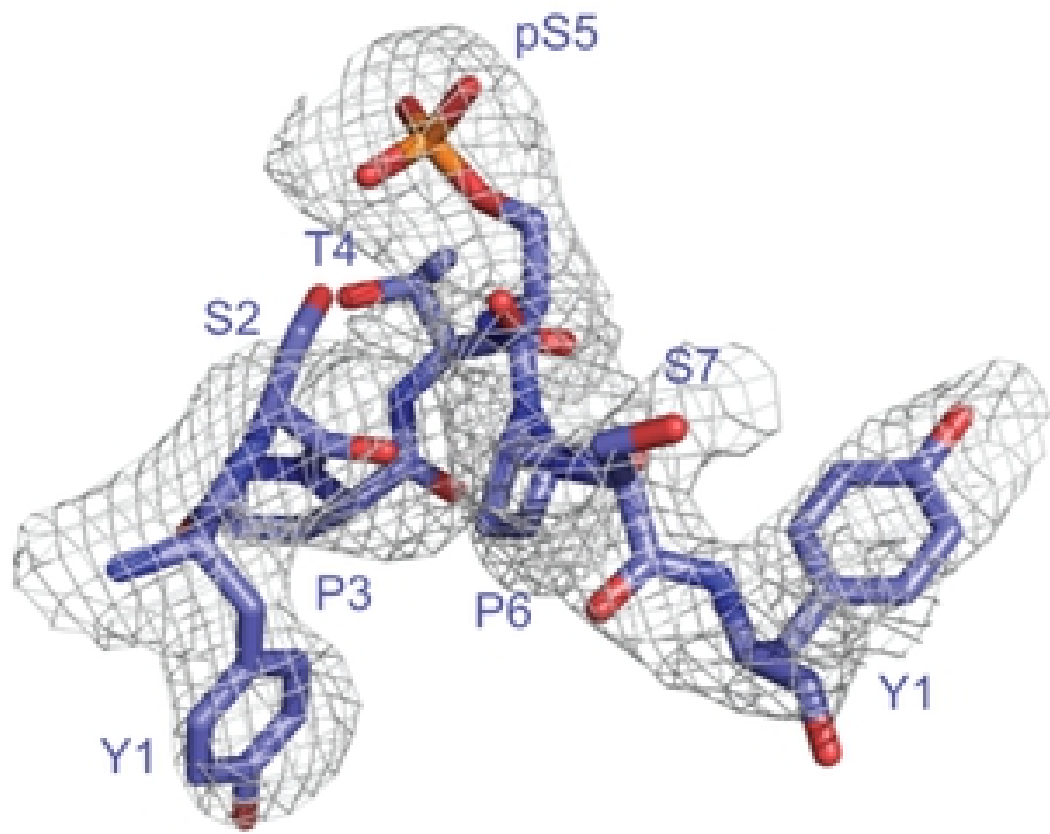

Fo-Fc omit map for CTD peptide contoured at $2.7 \sigma$ 


\section{Figure S2}

A B/Memphis/13/03 CTD site 2B

CTD-unbound

CTD-bound

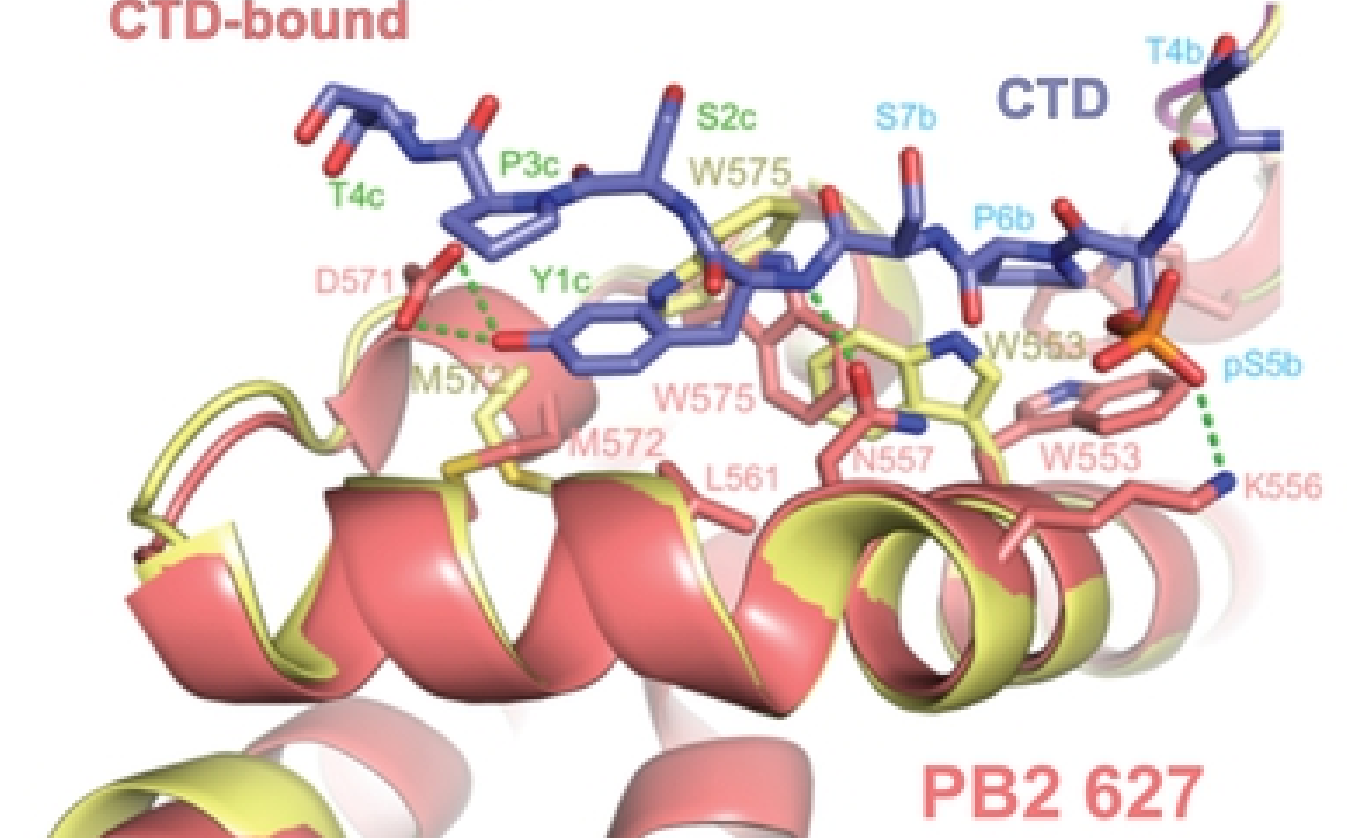

bioRxiv preprint doi: https://doi.org/10.1101/2022.02.04.479088; this version posted February 4, 2022. The copyright holder for this

preprint (which was not certified by peer review) is the author/funder, who has granted bioRxiv a license to display the preprint in

C CTD site 1A
B A/Zhejiang/DTID-ZJU01/2013(H7N9) CTD site 2A

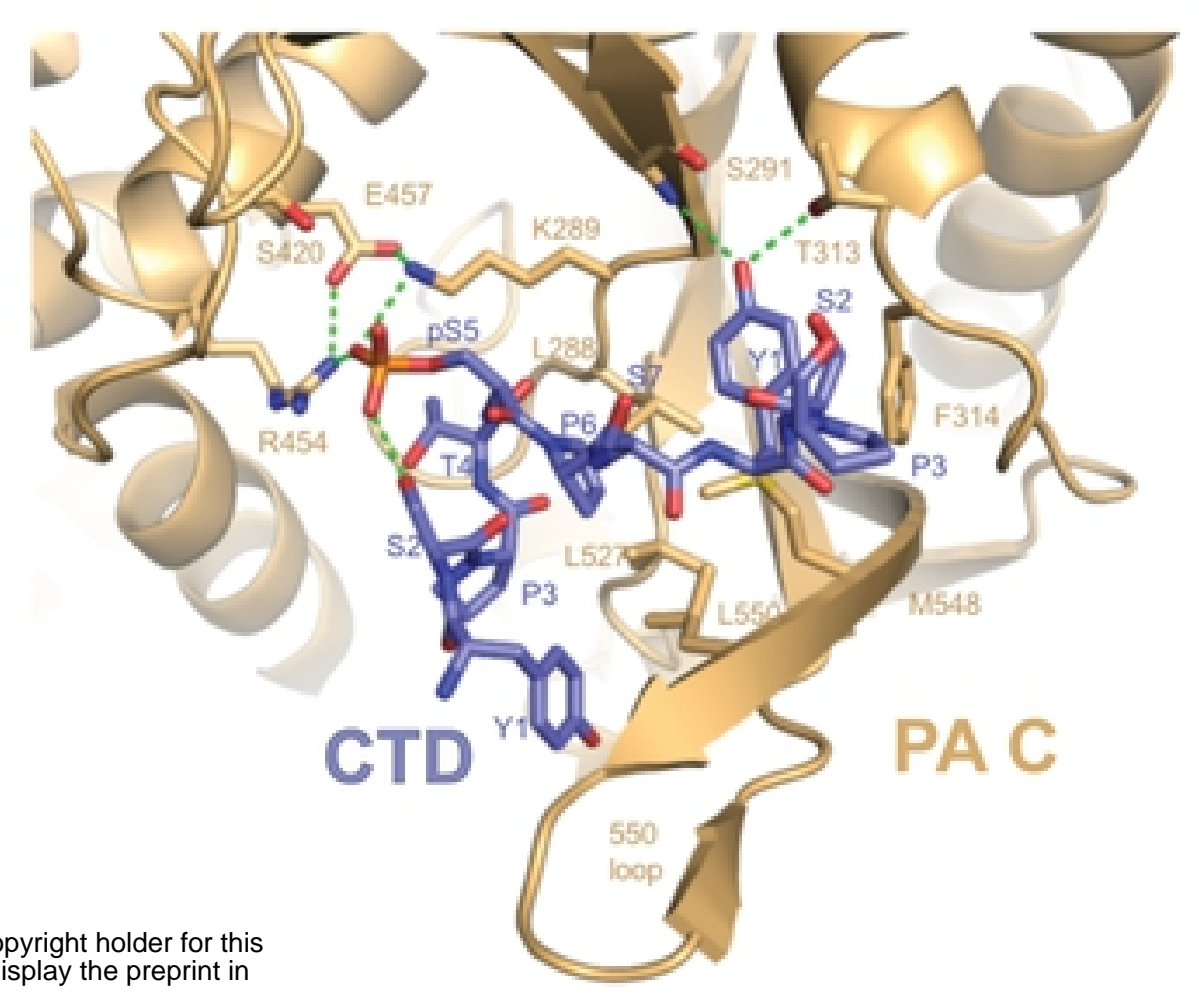

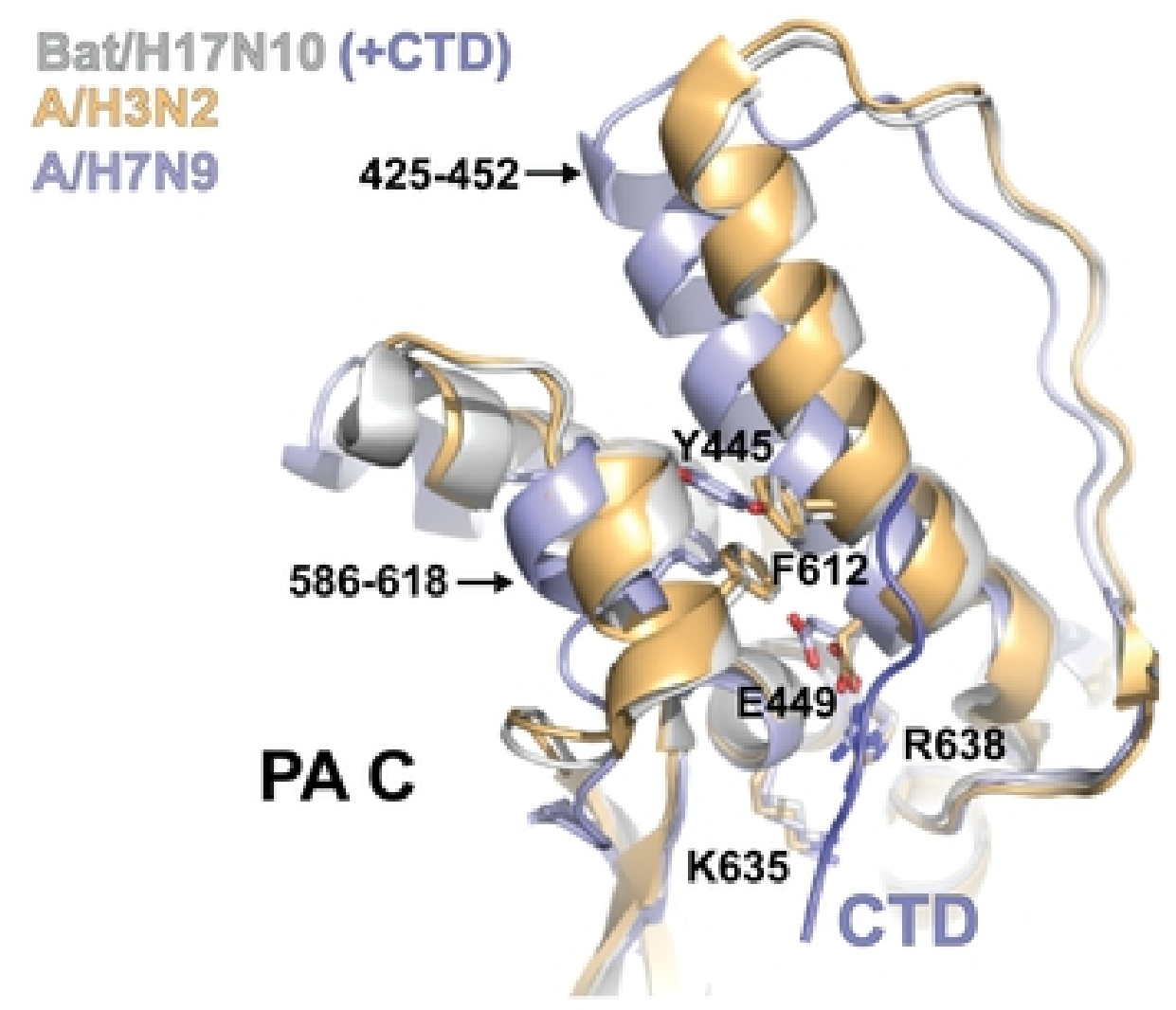




\section{Figure S3}

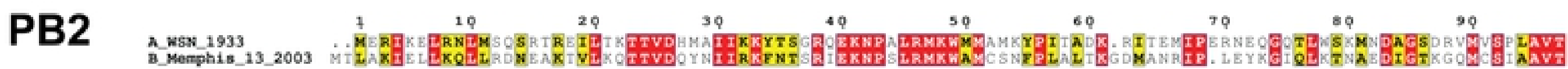

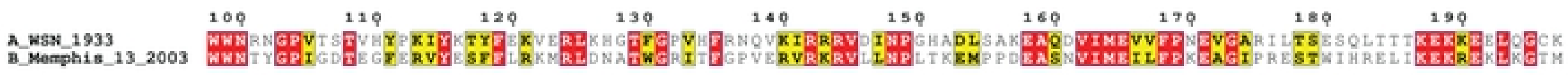

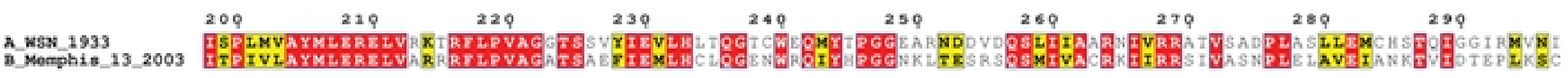

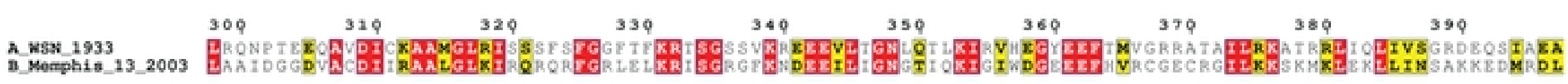

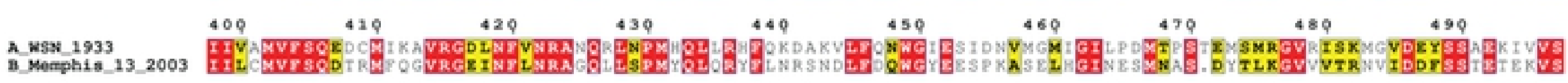

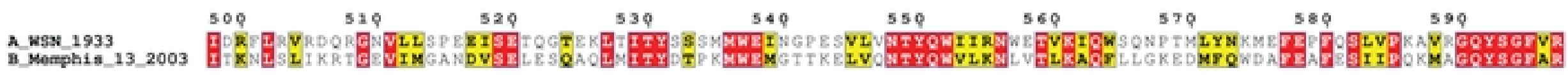

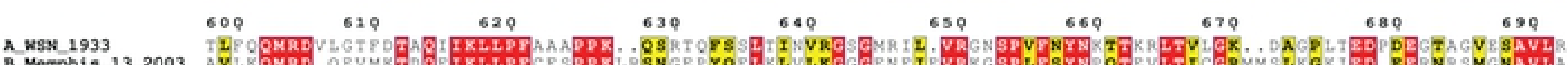

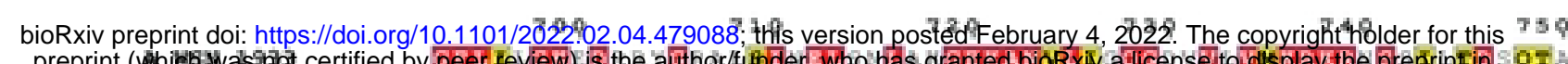

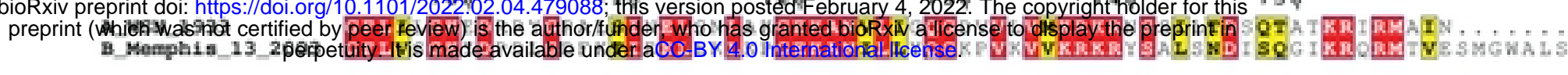

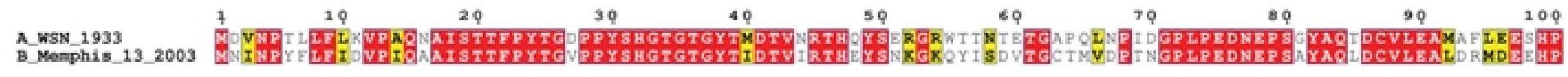

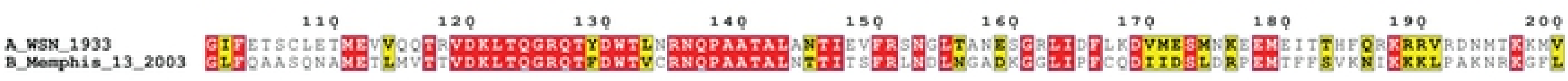

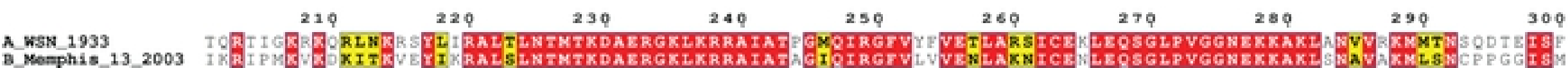

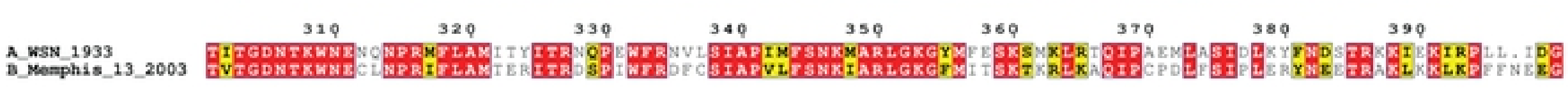

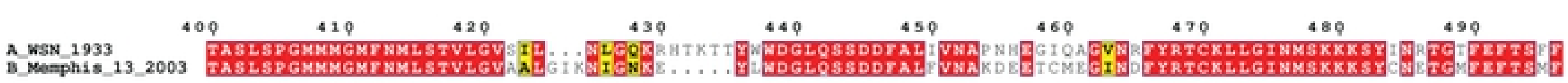

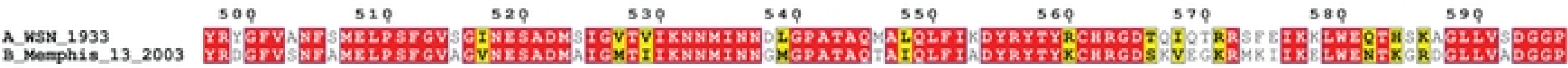

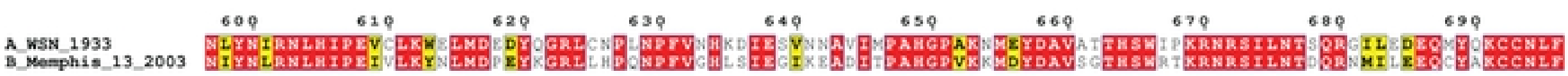

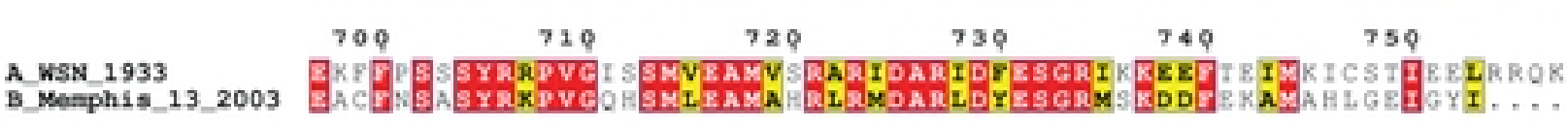

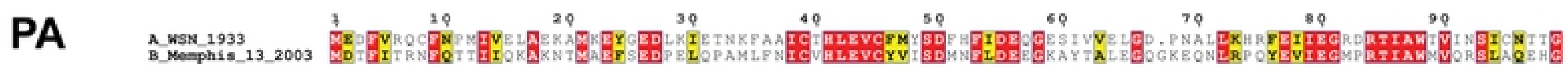

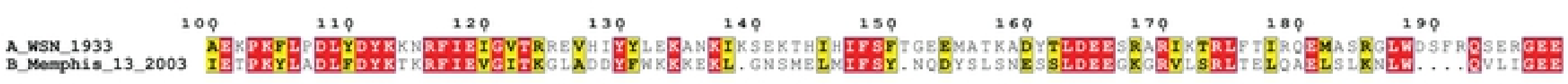

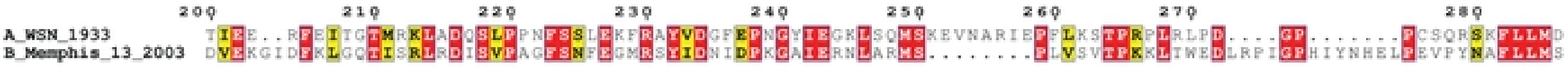

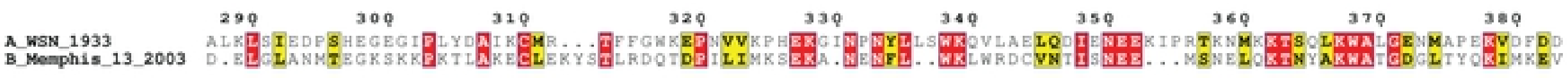

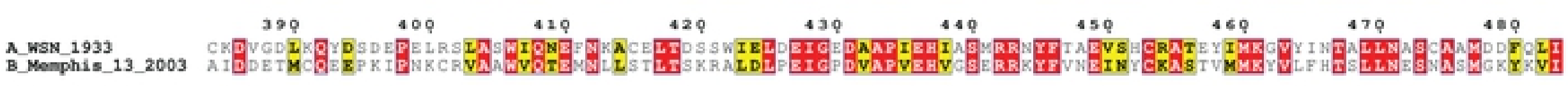

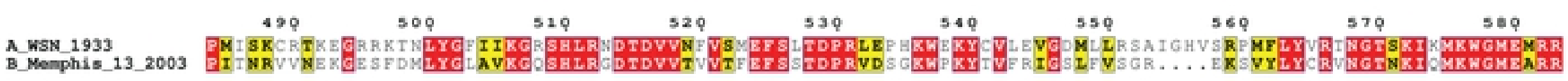

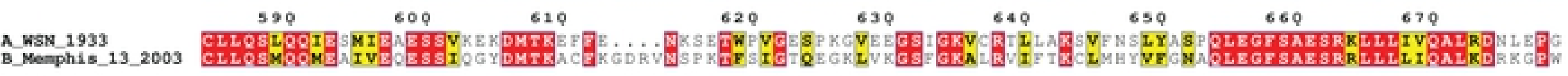

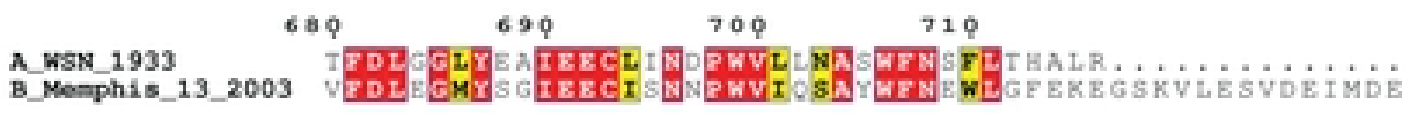


Figure S4

A

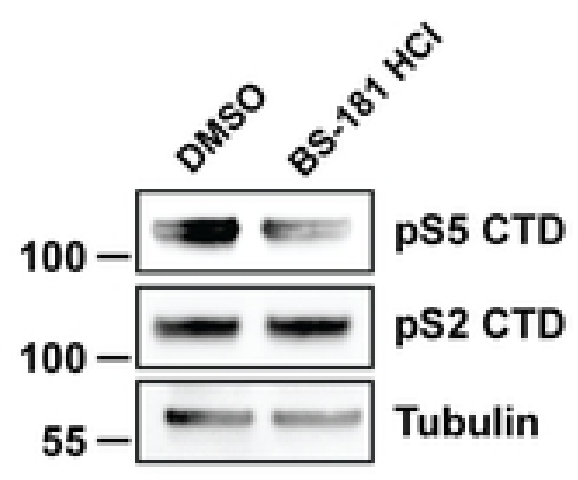

B

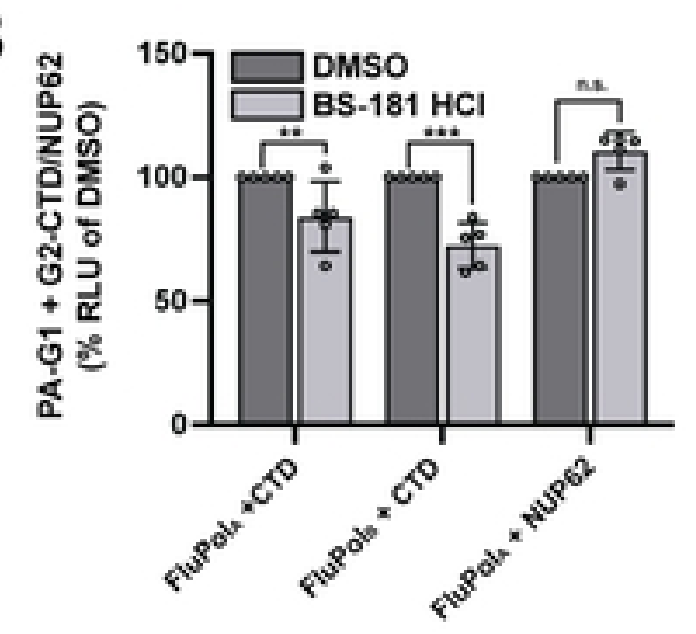

bioRxiv preprint doi: https://doi.org/10.1101/2022.02.04.479088; this version posted February 4, 2022. The copyright holder for this preprint (which was not certified by peer review) is the author/funder, who has granted bioRxiv a license to display the preprint in
perpetuity. It is made available under aCC-BY 4.0 International license. 
Figure S5
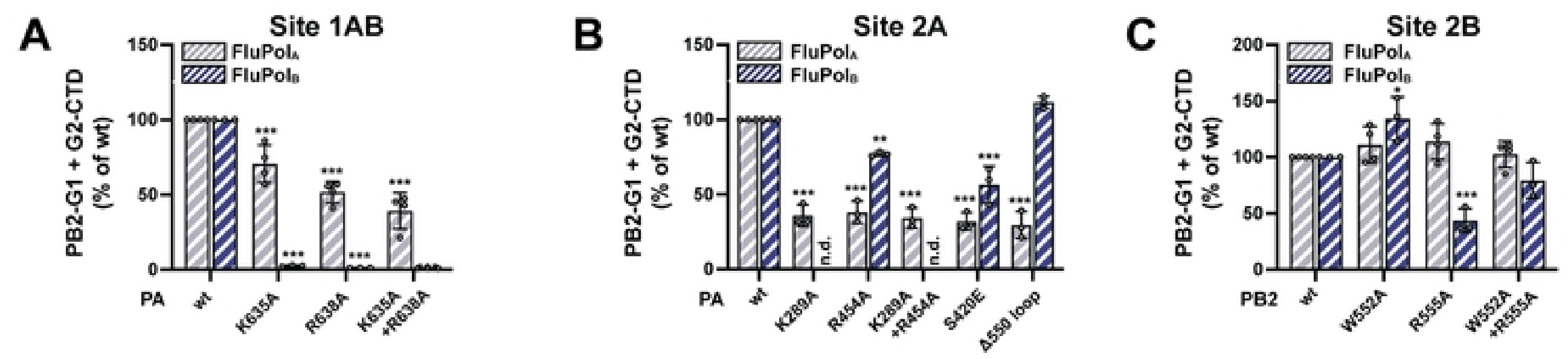

bioRxiv preprint doi: https://doi.org/10.1101/2022.02.04.479088; this version posted February 4, 2022. The copyright holder for this preprint (which was not certified by peer review) is the author/funder, who has granted bioRxiv a license to display the preprint in perpetuity. It is made available under aCC-BY 4.0 International license. 
Figure S6

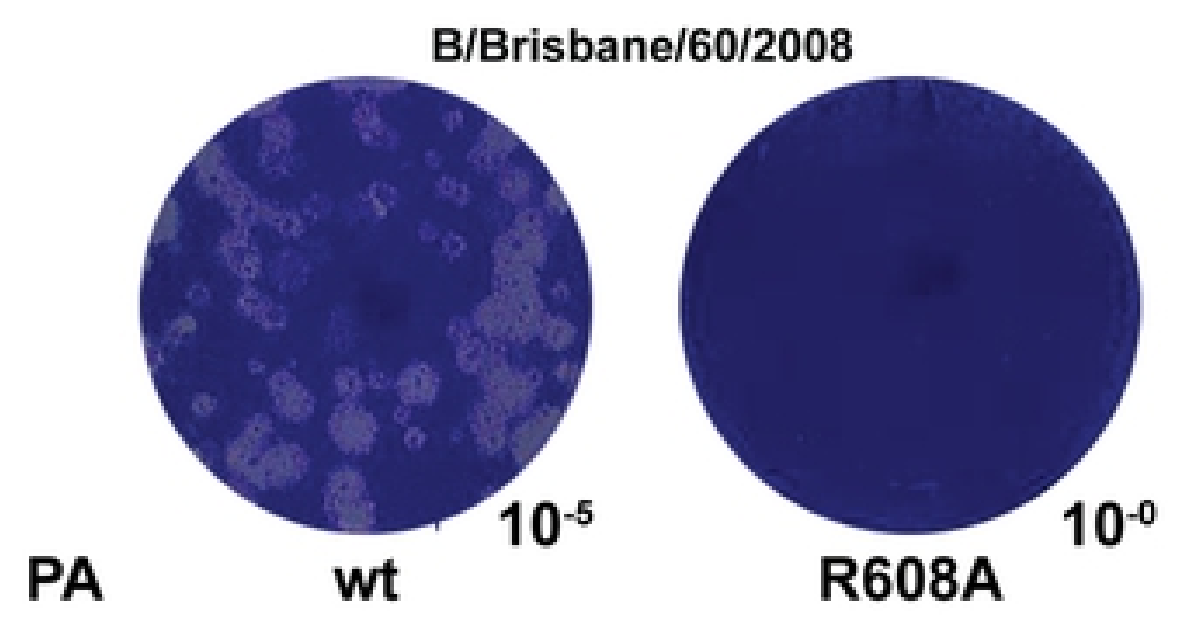

bioRxiv preprint doi: https://doi.org/10.1101/2022.02.04.479088; this version posted February 4, 2022. The copyright holder for this preprint (which was not certified by peer review) is the author/funder, who has granted bioRxiv a license to display the preprint in
perpetuity. It is made available under aCC-BY 4.0 International license. 


\section{Figure $\mathbf{S 7}$}

Sus_serof Equus_caballus Homo sapiens Canis lupus Mus musculus Gallus gallus Anas platyrhyneos

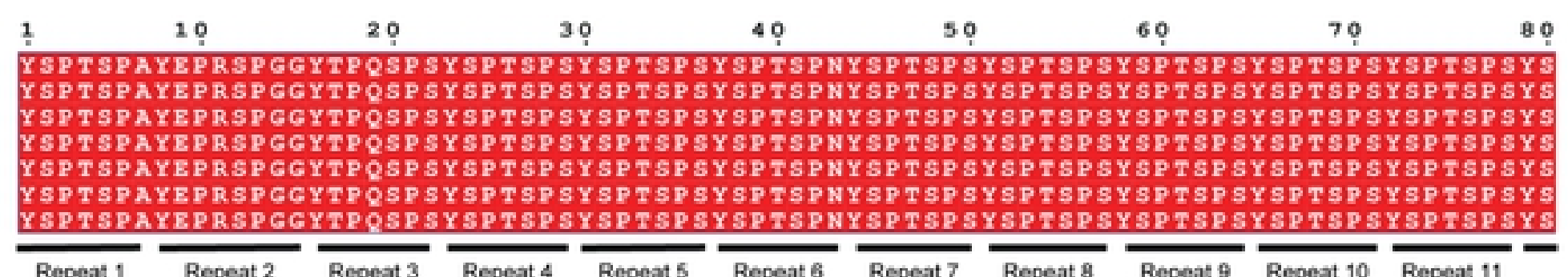

Sus_scrofa Equas caballus Homo_sapiens Canis lupus Mus =usculus Gallus_gallus Anas platyrhyncos

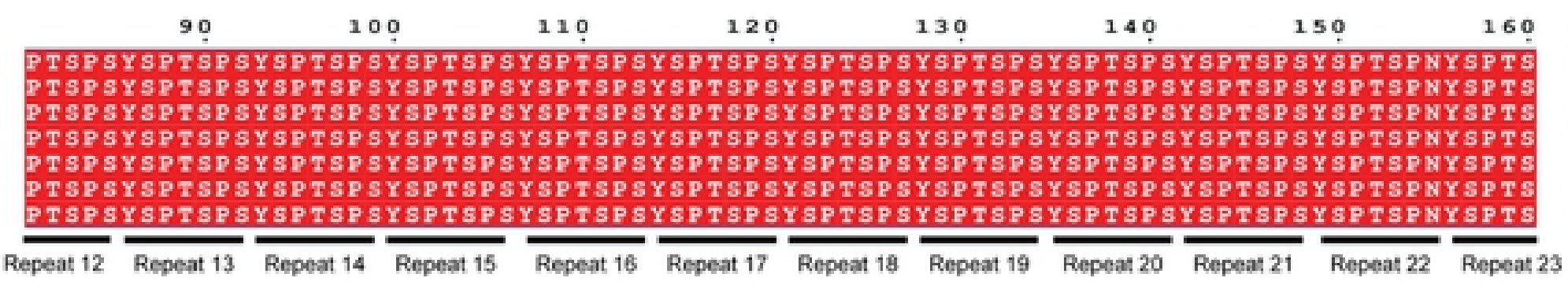

Sus_serofa

$170+180$

190

200

210

220

230

240 PNYTP TSP SY SP TSP SY SP TSPNYTP TSPNY SP TSP SY SP TSP SY SPTSP SYSP SSPRYTPQSPTYTP SSP SY SP SSP SY bioRxiv prepinu doiclatips $1 /$ doisorg/10. wholct waspobegrtified by pe canis 1upus perpetuly Mus musculus Gallus gallus Anas_platyrhyneos

$\overline{\text { Repeat } 24} \overline{\text { Repeat } 25} \overline{\text { Repeat } 26} \overline{\text { Repeat } 27} \overline{\text { Repeat } 28} \overline{\text { Repeat 29 }} \overline{\text { Repeat } 30} \overline{\text { Repeat } 31} \overline{\text { Repeat } 32} \overline{\text { Repeat } 33} \overline{\text { Repeat } 34}$

Sus_scrof

Equus caballus

Bomo_sapiens

Canis_lupus

Mus_=usculus

Gallus gallus

Anas_platyrhyncos

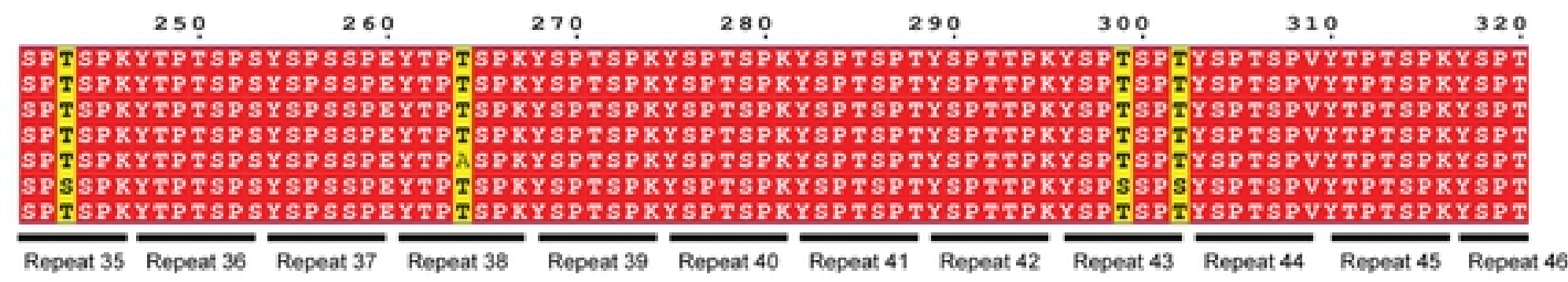

us_seror

Equus_caballus

Homo_sapiens

Canis_lupus

Mus musculus

Gallus gallu.

Anas_platyrhyncos

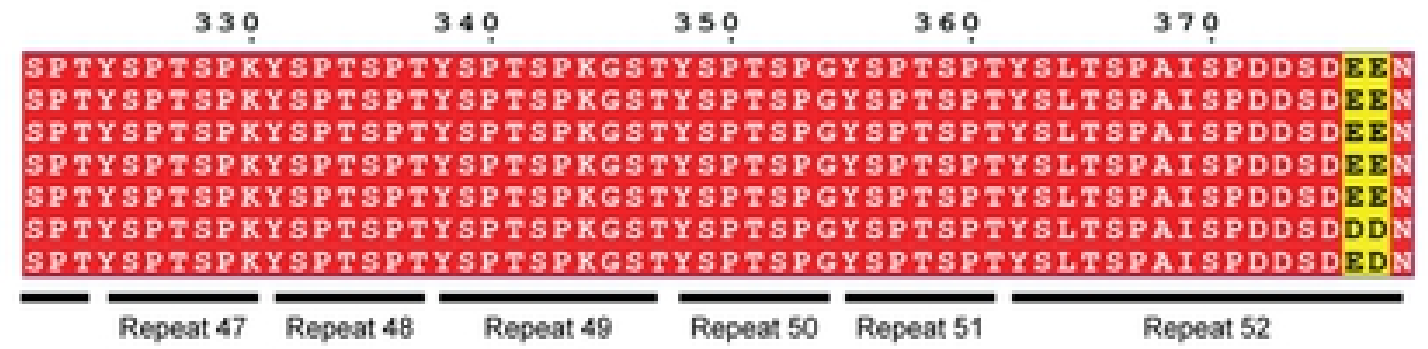

